TAO, Vol. 11, No. 4, 789-832, December 2000

\title{
Improved Treatment of Surface Evapotranspiration in a Mesoscale Numerical Model \\ Part II: Via the Assimilation of Satellite Measurements
}

\author{
Chia-Rong Chen ${ }^{1,}{ }^{*}$ and Peter J. Lamb ${ }^{2}$ \\ (Manuscript received 22 October 1998, in final form 4 May 2000)
}

\begin{abstract}
In part I of this research, it was shown that the simplified bucket method in the PSU/NCAR MM4 system had an apparent tendency to overestimate surface evapotranspiration (ET) when the long-term observational data from the Atmospheric Radiation Measurement program are used for verification. It was demonstrated that a Penman-Monteith (PM) method could effectively reduce the degree of overestimating surface ET. An examination of the impact of satellite data insertion, using a variational Four-Dimensional Data Assimilation (FDDA) technique proposed by Gal-Chen $(1983,1986)$, on the model's estimation of surface $E T$ is performed in the second part of this research. It shows that when the bucket method is in use the assimilation of the Geostationary Operational Environmental Satellite (GOES) temperature measurements helps the model make better estimation of surface ET owing to a significant decrease of potential ET resulting from a pronounced decrease of skin temperature and the associated moisture gradient at the ground surface. When the PM method is in use, the assimilation of GOES data tends to decrease the temperature and the associated mixing ratio depression at the lowest model level during the data assimilation period, and thus, the potential ET is decreased during the succeeding simulation period. Therefore, the model using the PM method is able to more correctly estimate latent heat flux after the data assimilation period. It reveals that Gal-Chen's FDDA algorithm of assimilating GOES data provides the model with the PM method a greater possibility of yielding the most accurate estimation of surface ET. The GOES data insertion would allow the model using the bucket method to gain a higher probability of making a more accurate estimation of latent heat flux than the model using the PM method without GOES data insertion. Even only satellite data
\end{abstract}

\footnotetext{
${ }^{1}$ Meteorological Satellite Center, Central Weather Bureau, Taipei, Taiwan

${ }^{2}$ School of Meteorology, University of Oklahoma, Norman, Oklahoma, USA

${ }^{*}$ Corresponding author address: Dr.Chia-Rong Chen, 64 Kung-Yuan Road, Meteorological Satellite

Center, Central Weather Bureau, Taipei, Taiwan 10039; Email: crchen@msc.cwb.gov.tw
} 


\begin{abstract}
insertion will enable the model to show a better estimation of surface ET. A nudging technique is shown to enhance the advantages of the proposed FDDA algorithm by making the model generate a more realistic estimation of surface ET. The nudging technique results in a further decrease of the skin temperature, temperature at the lowest model level and the accompanying moisture content at the ground surface and at the lowest model level during the data assimilation period.
\end{abstract}

(Key words: Evapotranspiration, Four dimensional data assimilation, Nudging)

\title{
1. INTRODUCTION
}

Over the last several decades there has been steady improvement in the forecasting of large-scale weather systems by Numerical Weather Prediction (NWP) models. The problem of solving the governing hydrodynamic equations is well known as an initial-value problem. If the present state of the atmosphere is not accurately known, it is also impossible to have a "perfect" numerical model to accurately predict the future state of the atmosphere. There are several types of observations that are useful in defining the mesoscale state of the atmosphere for numerical modeling. One is geostationary satellite data with sounding capability, and another is Doppler radar data. These can provide the detailed structure of mesoscale features as initial conditions for numerical models in order to make accurate predictions. In this study the retrievals from the geostationary satellite are assimilated into the modeling system in the hope of improving the model performance.

The concept of merging two separate functions of objective analysis and numerical model prediction to better describe the state of the atmosphere is now commonly described as FourDimensional Data Assimilation (FDDA, Chamey et al. 1969). The fulfillment of this concept has proven to lead to a major advance in NWP (Morel 1981; Roads and Maisel 1991; Derber and Wu 1998). Two major types of FDDA techniques have been used operationally and in research. The first is an intermittent process of initializing an explicit prediction model, using the subsequent forecast (typically 3-12 hour) as a first guess in a static 3-dimensional objective analysis step. In this technique, all the available non-conventional observations from satellites and commercial airplanes, etc., are fully utilized during the process of objective analysis, which is then followed by a period of model integration, before the process for another data assimilation cycle is repeated. Techniques based on intermittent data assimilation have been used at most of the world's major operation centers, such as the United States National Centers for Environmental Prediction, (DiMego 1988), and the European Center for MediumRange Weather Forecasts (ECMWF), (Hollingsworth 1986). The second major type of FDDA technique is a continuous dynamic assimilation with forcing functions being added to the governing model equations to gradually "nudge" the model state toward the observations (Anthes 1974; Davies and Turner 1977; Hoke and Anthes 1976). The later technique has been used operationally at the United Kingdom Meteorological Office (UKMO), for both global (Lyne et al. 1982) and regional (Bell 1986) data assimilation systems. In this research an 
intermittent FDDA algorithm devised by Gal-Chen $(1983,1986)$ is utilized. An analysis-nudging technique is also designed to further enhance the advantage of this FDDA method. Basic issues concerning nudging techniques can be found in Stauffer and Seaman $(1990,1991)$.

Cram and Kaplan (1985) assimilated horizontal gradients of satellite-derived temperature and moisture fields into a mesoscale model by variationally blending them with model-simulated gradient during the objective analysis step of an intermittent FDDA scheme. Their variational VAS (Visible Infrared Spin Scan Radiometer, VISSR, Atmospheric Sounder) model impact approach accommodated the mesoscale horizontal structure of the VAS retrievals, but did not include vertical coupling between vertical model levels. Although the Cram and Kaplan experiment showed that using VAS temperature retrievals yielded a positive impact on the convective destabilization in their model, the net result of their study was that the impact of VAS was generally small. Gal-Chen et al. (1986) added vertical coupling to the assimilation cycle by using a three-dimensional variational approach within the intermittent assimilation framework. In Gal-Chen's technique, the mean vertical structure and horizontal gradients inferred from simulated satellite data were inserted into the model without destroying the fine vertical structure created by the model. Thus, the strengths of the satellite observing system (increased temporal and horizontal resolution) are emphasized while avoiding its major weakness (poor vertical resolution). Aune et al. (1987) applied a variation of this approach by assimilating satellite-derived thickness data into an adiabatic regional-scale model. They found that Gal-Chen's algorithm did have a positive impact on the model's prediction of the strength and movement of a dry frontal zone. The general properties of the old VAS system, the new Geostationary Operational Environmental Satellite (GOES) continuous sounders and the associated temperature and moisture retrieval algorithms are reported in Chester et al. (1982), King (1956), Kaplan (1959), Liou (1980), Chedin et al. (1985), Smith (1970, 1983), Jedlovec (1986), Kalnay et al. (1990), Thompson (1992), Mensel and Purdom (1994), and Hayden et al. (1996).

It is worth mentioning that the temperature measurements from the GOES, which are used in this study, are retrieved quantities based on the radiance observed by the sounders residing on the satellite. The "retrieval" or "inversion" process, whereby satellite radiances are converted to atmospheric temperature profiles, has some rather subtle properties and error characteristics (Eyre 1987). The inversion problem is mathematically ill-posed, i.e., an infinite number of profiles are consistent with the radiance measurements, and additional constraints are required to choose between the possible profiles. This means that the retrieved profile will contain both observed information from the radiances and unobserved information imposed by the additional constraints. This leads to errors in the retrievals that are correlated in both the vertical and horizontal directions. These characteristics may make the data difficult to use "effectively" in conventional NWP analysis schemes. Thus, there is a growing trend in focusing attention on how some of the problems may be removed or minimized if the radiance information is used more directly within the NWP system. What needs to be addressed, is that the necessity for an "inversion" or "retrieval" operation associated with the use of satelliteobserved radiances is not removed, but is wansferred into the data assimilation system. Measures for directly assimilating radiance data were initiated by Eyre (1987). A preliminary impact study of directly assimilating radiance data on the forecasts of the ECMWF global model 
was presented by Eyre and Lorenc (1989) and Eyre et al. (1993). It shows that the use of cloudcleared satellite radiances directly in the construction of mass, momentum, and moisture fields in the Spectral Statistical Interpolation (SSI) analysis system (Parrish and Derber 1992, Derber et al. 1991) of the NCEP global analysis-forecast system, eliminates the need to first construct radiosonde-like temperature and moisture soundings from the radiance observations. During the test period, the new system produced large increases in forecast skill on the geopotential height and wind at all levels in the Southern Hemisphere, and throughout the troposphere in the Northern Hemisphere (Caplan et al. 1997).

In part I of this research (Chen and Lamb 1997, hereafter, CL97), a Penman-Monteith (PM) method of estimating potential evaporanspiration (ET) over land area is introduced into the Pennsylvania State University/National Center for Atmospheric Research Mesoscale Model version 4 (PSU/NCAR MM4) system. The use of the PM method enables the model to have pronounced capability to correctly estimate the latent heat flux, sensible heat flux, net radiation at the ground surface, low-level temperature and moisture, etc. Gal-Chen's FDDA technique of assimilating satellite-derived temperature is applied in the second part of this research to study the impact of satellite data insertion on the model's estimation of surface ET. Issues of geostrophic adjustment within a mesoscale model due to the insertion of mesoscale temperature information, a brief discussion of Gal-Chen's FDDA algorithm and the design of an analysis-nudging scheme to enhance Gal-Chen's FDDA algorithm are outlined in Section 2 and the appendix. The necessity and outcome from the observing system simulation experiments are in Section 3. Comparisons of the estimated latent heat flux to that from the use of the bucket and PM methods, with or without GOES data insertion, are in Section 4. Section 5 contains the final summary and conclusions of this research.

\section{THE VARIATIONAL FDDA TECHNIQUE AND THE OBSERVATIONAL DATA SET USED FOR VERIFICATION}

To study the impact of satellite data insertion on the PSU/NCAR MM4 (Anthes 1977; Anthes and Warner 1978; Anthes et al. 1987) system's estimation of surface ET, a variational FDDA technique initiated by Gal-Chen (1983), for assimilating satellite retrievals, is utilized in this study. In $1983 \mathrm{Gal}$-Chen proposed a variational FDDA algorithm which makes good use of the improved temporal (up to every half hour, in principle) and horizontal spatial (30 to $60 \mathrm{~km}$ ) resolutions of geostationary satellite data, such as the old VAS residing on GOES-7 or the new continuous sounder deployed on GOES-8 and GOES-9. The concepts of this FDDA technique is that the model's predicted temperature and the adjusted temperature are as close as possible to each other, in a least-square sense, during the data assimilation period, and at the same time, the adjusted temperature should match the requirements imposed by the GOES observation. Namely, the adjusted temperature is subject to the constraint set by the GOES measurements. In practice, Gal-Chen's technique is to:

(1) replace the model's predicted vertically-averaged temperatures (including all of the vertical

levels in the atmosphere and the ground surface) with those derived from satellite data (illustrated in Fig. 2.1); and 


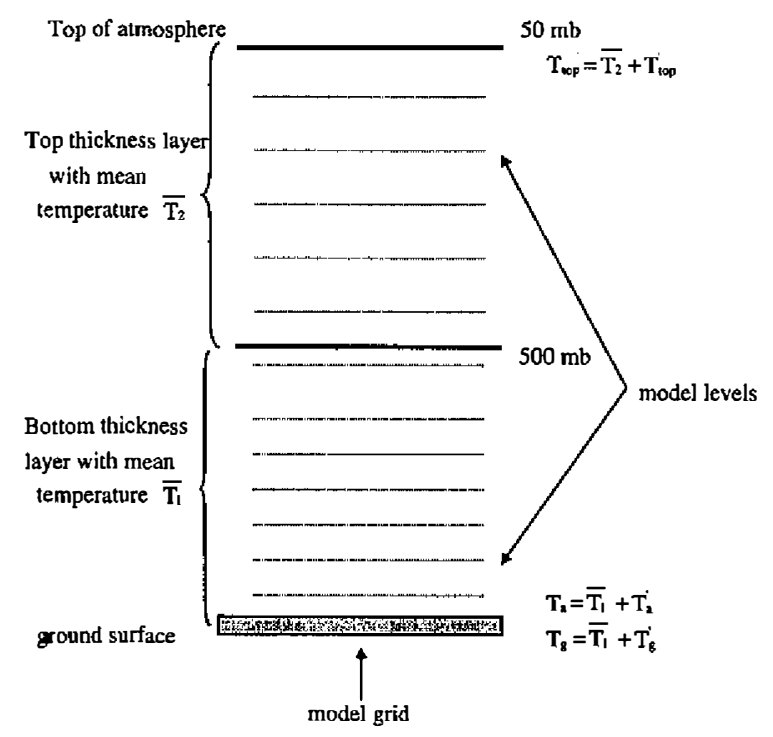

Fig. 2.1. Illustration of Gal-Chen's (1983) FDDA scheme. The model's atmosphere on each model grid can be divided into two thickness layers (separated by bold solid lines): the bottom one is from ground surface to $500 \mathrm{mb}$, and the top one from 500 to $50 \mathrm{mb}$. Each thickness layer contains several model levels (dashed lines). The mean temperature of each thickness layer is computed based on the model levels in that layer. As shown in this figure, $\overline{\mathrm{T}_{1}}$ and $\overline{\mathrm{T}_{2}}$ are the mean temperature for the top and bottom layer, respectively. Therefore, the skin temperature $T_{g}$, temperature at the lowest model level $T_{a}$, and temperature at the top of the model atmosphere $T_{\text {top }}$ can be expressed as $\bar{T}_{1}+T_{g}^{\prime}, \bar{T}_{1}+T_{a}^{\prime}$, and $\bar{T}_{2}+T_{\text {top }}^{\prime}$, respectively. The corresponding mean temperature of each thickness layer is computed based on the satellite observed temperature in the same layer. E.g., $\bar{T}_{1}^{\text {sat }}$ for layer 1 and $\overline{\mathrm{T}}_{3}^{\text {sat }}$ for layer 2 . Gal-Chen's FDDA scheme is to replace $\overline{\mathrm{T}}_{1}$ and $\overline{\mathrm{T}}_{2}$ by $\overline{\mathrm{T}}_{1}^{\text {sat }}$ and $\overline{\mathrm{T}}_{2}^{\text {sat }}$ on each model grid, respectively, during the data assimilation period.

(2) adjust the model's geopotential fields according to the model's original geopotential fields and the newly modified geopotential fields (based on the newly adjusted temperature fields), such that the imbalance between the mass and wind fields due to satellite data insertion is minimized.

In this way, information from larger vertical scales provided by satellite measurements is inserted into the modeling system, while that from finer vertical scales generated by numerical models is left untouched during the satellite data assimilation period. The mathematical formulation of Gal-Chen's algorithm are briefly reviewed in the appendix.

At first glance, it is unclear whether the insertion of satellite-derived temperature data will effectively modify the wind and moisture fields, and consequently the latent heat flux (LHF) 
coming from the ground surface, in a mesoscale model. Traditional linear theory (Rossby 1937, 1938; Cahn 1945; Bolin 1953; Ökland 1970; Blumen 1972; Schoenstadt 1977) states that the critical parameter in a geostrophic adjustment process is the Rossby radius of deformation, $L_{R}$. For a shallow water system, this radius is defined as $L_{R}=\frac{\sqrt{g H}}{f}$, where $g$ is the acceleration due to gravity, $\mathrm{f}$ the Coriolis parameter, and $\mathrm{H}$ the equivalent depth of the weather or fluid system. For scales that are smaller than $\mathrm{L}_{R}$, the mass field should adjust to the wind field, while for scales that are larger than $\mathrm{L}_{\mathrm{R}}$, the wind field adjusts to the mass field. As discussed by Kuo et al. (1987), for a continuously stratified atmosphere, the adjustment problem should be examined by separating the atmosphere's vertical structure into several vertical modes, in order to determine the equivalent depth of each mode. For the MM4 system used in this research, Errico (1986) performed a vertical mode analysis and found that the equivalent depth $(\mathrm{H})$ of the first external mode is $6,890 \mathrm{~m}$, while that of the first internal mode is $476 \mathrm{~m}$. For the smallest internal mode, the equivalent depth is only $0.003 \mathrm{~m}$. With such a wide range of equivalent depths, the corresponding Rossby radius of deformation ranges from $2,772 \mathrm{~km}$ to less than $2 \mathrm{~km}$. Consequently, if the inserted data are projected onto several vertical modes on horizontal scales both larger and smaller than $\mathrm{L}_{\mathrm{R}}$, simultaneous adjustment in the mass and wind fields will occur. Hence, the information provided by remotely sensed temperature data that is assimilated would remain in the modeling system and render some impact on the model's behavior after the data assimilation period (see also Gal-Chen 1983; and Chen 1996).

The observational data sets used for verification are those from the Southern Great Plain (SPG) Atmospheric Radiation Measurement (ARM) site (Stokes and Schwartz 1994). The estimated surface ET from the model is contrasted with the corresponding observations from the SGP ARM site. The measurement of surface ET and the associated observational error characteristics are discussed in Chen (1996). In addition, observational data, such as LHF, sensible heat flux (SHF), net radiation flux at the ground surface $\left(\mathrm{R}_{\text {net }}\right)$, near surface air temperature, near surface moisture content and surface pressure, taken from three observational stations in the SGP ARM site (i.e., E9 at $36.43^{\circ} \mathrm{N}, 98.28^{\circ} \mathrm{W}$; E13 at $36.6^{\circ} \mathrm{N}, 97.48^{\circ} \mathrm{W}$; and E15 at $37.13^{\circ} \mathrm{N}, 97.26^{\circ} \mathrm{W}$, as shown in Fig. 3.1 of CL97) are averaged and used for verification against model simulation results from the model grid that is closest to the 3 SGP ARM observation stations, which is located at $36.24^{\circ} \mathrm{N}$ and $97.64^{\circ} \mathrm{W}$. Net radiation flux at the ground surface $R_{\text {net }}$ is defined as : $R_{\text {net }}=(1-\alpha) S \downarrow+L_{w} \downarrow-\varepsilon_{g} \sigma T_{g}^{\prime 4}$, where $\alpha$ is the albedo; $S$ is the solar constant, so $(1-\alpha) S \downarrow$ is the net shortwave radiative flux; $L_{w} \downarrow$ is the downward longwave radiative flux; $\varepsilon_{\mathrm{g}}$ is the emissivity of the ground surface; $\sigma$ is the Stefan-Boltzmann constant; and $\varepsilon_{\mathrm{g}} \sigma \mathrm{T}_{\mathrm{g}}^{\prime 4}$ is then the outgoing longwave radiative flux from the ground surface.

\section{OBSERVATION SYSTEM SIMULATION EXPERIMENTS (OSSES)}

Some OSSEs and real data assimilations (next section) are conducted to study the impact of satellite data insertion on the model performance using Gal-Chen's FDDA algorithm. Factors leading to the impact on model simulations are examined. It should be pointed out that some quantities used to calculate the potential ET in the bucket and PM methods, such as the 


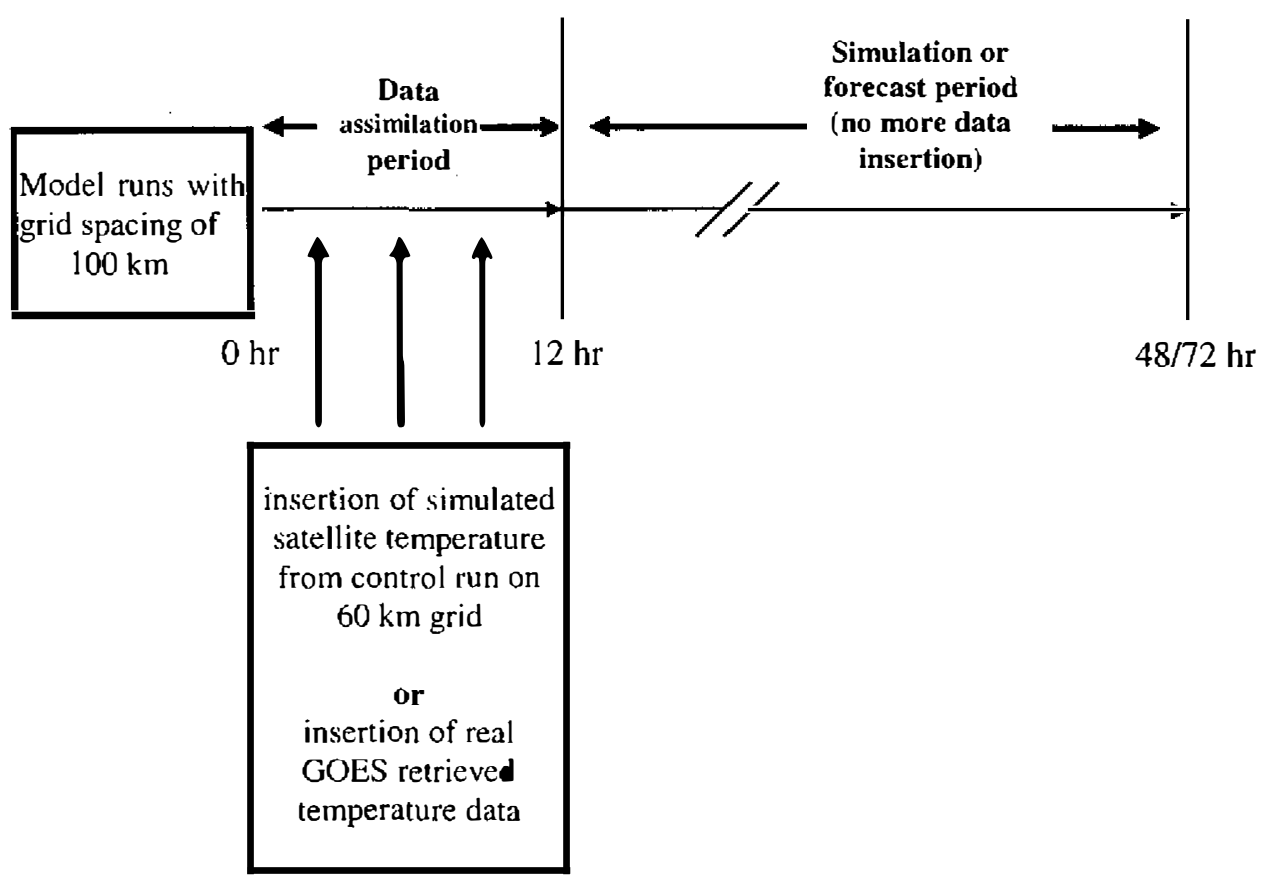

Fig. 3.1. The data assimilation methodology. For the observing system simulation experiment, simulated satellite data are assimilated into the model during data assimilation period. For the real data assimilation, GOES data are inserted into the model during the data assimilation period. The simulation or forecast period lasts for 36 or 60 hours.

air density at the lowest model level, friction velocity, Monin-Obukhov length, roughness length and stability parameter, are not routinely observed at the SGP ARM site, and some are parameterized based on different surface layer similarity theories (Anthes et al. 1987). In other words, there are no complete observational data that can be used as verification to examine the quantities responsible for the adjustment of LHF estimation, due to satellite data insertion. Therefore, there is a need to perform the OSSEs to quantitatively understand what variables are adjusted, owing to satellite data insertion, and their relative contributions to the model estimation of LHF. The atmosphere in the control run of the OSSE is regarded as the "true" atmosphere. Many unobserved quantities from the control run serve as the "observations" from the "true" atmosphere. One can then utilize these unobserved quantities to clearly identify how the variables in the surface layer are adjusted, and recognize the factors influencing the model's estimation of surface ET as simulated satellite data are inserted. Temperature fields from the model with a grid distance of $60 \mathrm{~km}$ are regarded as the satellite retrieved temperature and are assimilated into model runs with a grid distance of $100 \mathrm{~km}$. It is then possible to quantitatively examine the impact of satellite data insertion on the model performance. 


\subsection{Updating and Objective Analysis Procedures}

As has been done in other simulation experiments, a control run was designed to simulate aspects of the real atmosphere. Once the control run was defined, the atmosphere simulated by the control run was henceforth treated as the "real" atmosphere. The model run with a grid distance of $60 \mathrm{~km}$ is chosen to be the control run because the approximate resolution of geostationary satellite data is $60 \mathrm{~km}$. Next, the simulated atmosphere is "observed" in a manner which is somewhat similar to that of a geostationary satellite with sounding capability. According to the concept of Gal-Chen's FDDA technique, an assumption is made that only vertically averaged temperatures between the surface and $500 \mathrm{mb}$ and between 500 and $50 \mathrm{mb}$ can be inferred from the satellite observations. Thus, the temperature profile "observed" by the geostationary satellite consists of two layers of mean temperature in the atmosphere (Fig. 2.1).

The same model with a grid distance of $100 \mathrm{~km}$ (M100, hereafter) using a smaller amount of sounding data (than the ones used for the initialization of the model with $60 \mathrm{~km}$ resolution) to constitute the initial condition is employed to assimilate the two layers of mean temperature "observed" by the satellite. During the time integration of the M100, there are periodic insertions of simulated satellite mean temperature to adjust the model's predicted temperature. This procedure essentially involves implementing the variational scheme discussed in Section 2. The updating or data assimilation period lasts for 12 hours (hrs). The frequency of satellite data insertion varies from 13 insertions (every hr) to one single insertion in the updating period. This assimilation procedure is designed to see whether the finer time resolution of geostationary satellite data can compensate for the poor vertical resolution. Once the data assimilation cycle is over, the integration of the M100 proceeds in its usual manner. Comparisons of surface ET from the M100 to that from the control run are then made to assess the impact of inserting simulated satellite data on the model's estimation of surface ET. A time line showing the sequence of the data assimilation and the succeeding simulation (or forecast) period is illustrated in Fig. 3.1.

In summary, the updating and objective analysis procedure consists of the following steps: 1) generating a simulated (or "real") atmosphere from the control run;

2) taking part of the domain of the control run, such as the inner square area shown in Fig. 3.2, as the available "satellite" measurement area with the temperature fields in the "satellite" measuring area then taken as the sounding retrievals;

3) deriving the mean temperature structure for the bottom half and top half of atmosphere from "satellite" observations;

4) objectively analyzing the available "satellite" mean temperature data in each layer onto the grids of the M100 by using the Cressman successive scan technique (Cressman 1959), in which four passes are used, with a smaller radius of influence for each pass, i.e., 635, 508, 381 , and $254 \mathrm{~km}$, respectively;

5) running the M100 (using a smaller amount of sounding data) and imposing a 12-hour data assimilation period with various satellite data insertion frequencies. The satellite data insertion frequencies range from every one hr (13 insertions), every $2 \mathrm{hrs}$ ( 7 insertions), every 3 hrs (5 insertions), every 4 hrs ( 4 insertions), every $6 \mathrm{hrs}$ ( 3 insertions), every $12 \mathrm{hrs}$ ( 2 


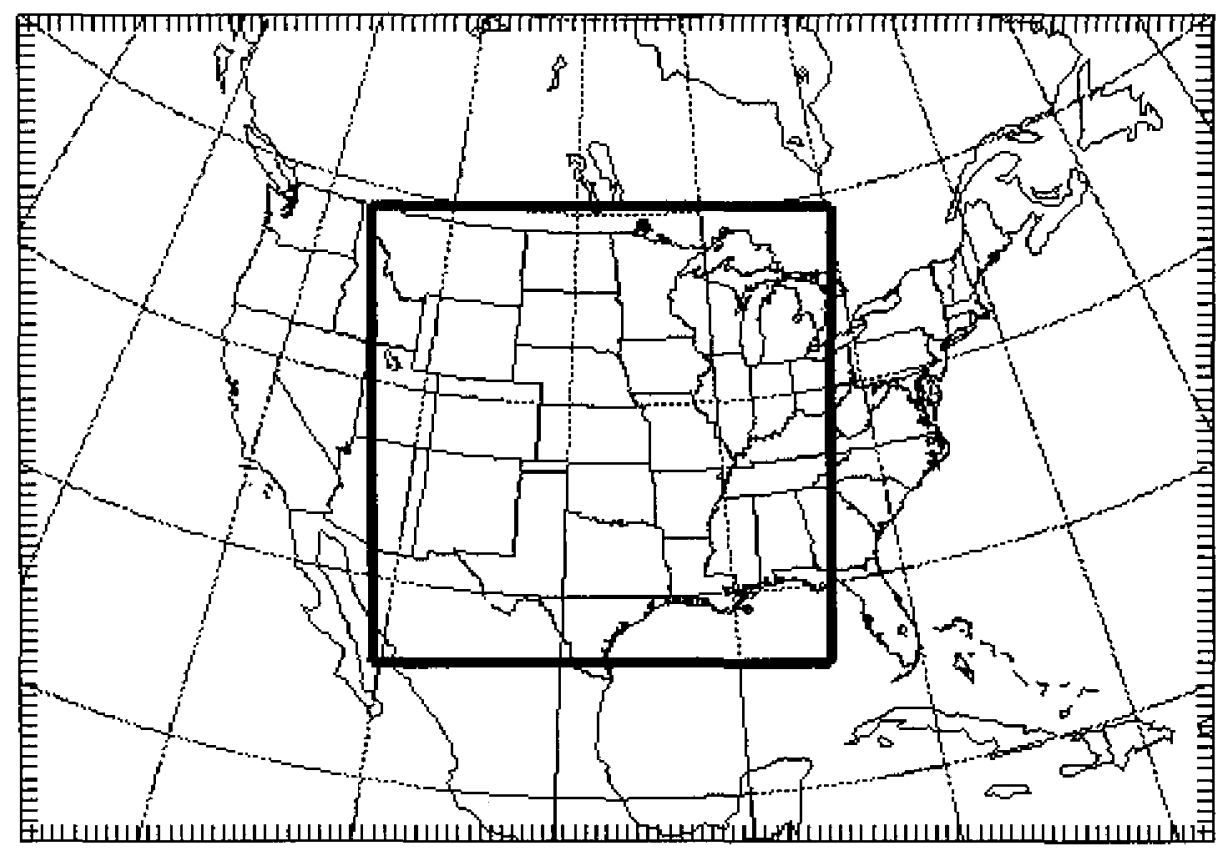

Fig. 3.2. The computational domain of the model used in this study. The inner square is the simulated satellite data area used in the observing system simulation experiment.

insertions) to only 1 insertion at the first hour of data assimilation period.

The purpose of inserting data at different frequencies is to examine (i) whether the "satellite" measurements would have a positive impact on the model's estimation of surface ET; (ii) whether more frequent "satellite" data insertion would create a more positive impact on the model's estimation of surface ET. At the end of the updating procedure, the M100 is integrated in a conventional way. The subsequent output in the forecast period from the M100 is compared to that from the control run. The degree of impact on the model's estimation of surface ET due to different "satellite" data insertion rates is then evaluated.

Root mean square (RMS) errors (unit: $\mathrm{Wm}^{-2}$ ) for estimating LHF from various data insertion rates during a $25-48 \mathrm{hr}$ forecast period are shown in Table 3.1. Hourly average surface ET due to 1, 7, and 13 times of "satellite" data insertion rate are shown in Fig. 3.3a, b and c, respectively. It can be seen that even a single "satellite" data assimilation can obviously reduce the amplitude differences of daytime surface ET when compared the case without satellite data insertion. On the other hand, a higher data assimilation rate does not cause the model to show better estimations of surface ET due to much more imbalance between mass and momentum fields being invoked by more frequent data insertion, as can be evaluated by the evolution of the noise parameter (Bleck 1977) during the data assimilation period (Fig. 3.4). In the case of more frequent data insertion, the model needs to take more time to remove the imbalance in the ensuing forecast period. Consequently, it shows that the model does not 
Table 3.1. Root mean square errors ( $\left.\mathrm{Wm}^{-2}\right)$ of model's (using the bucket method with a grid spacing of $100 \mathrm{~km}$ ) estimating latent heat flux owing to different simulated satellite data insertion frequencies during 25-48 hour forecast period which is 12 hours after the data assimilation period.

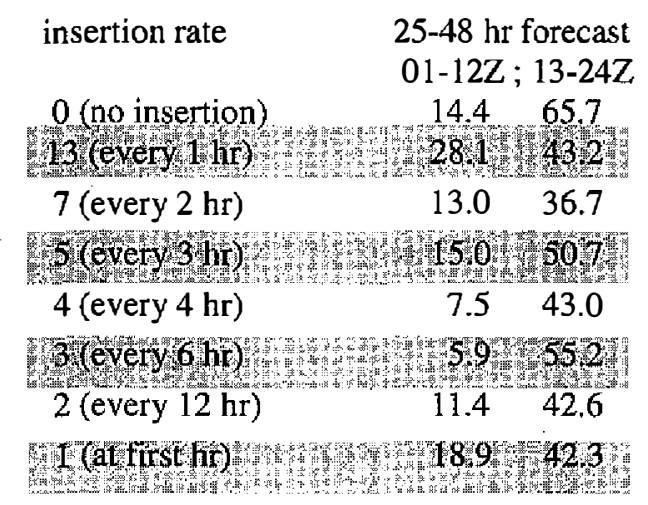

necessarily make better estimations of surface ET when there is a higher data assimilation rate, as shown in Fig. 3.3c and Fig. 3.4a. The RMS errors of estimating LHF which result from 7 data insertions are less than those resulting from 13 insertions (Table 3.1). The lesson learned from the experiment is, then, that a single "satellite" data insertion is good enough to force the model to improve its estimation of the surface ET.

\subsection{Discussion}

The formulation of the bucket method used by the MM4 is as follows:

$$
\mathrm{ET}=\mathrm{ML}_{\mathrm{v}} \mathrm{E}_{\mathrm{p}}
$$

M: moisture availability, ranging from 0 to 1 (CL97);

$\mathrm{E}_{\mathrm{p}}$ : potential ET; $\mathrm{L}_{\mathrm{v}}$ : latent heat of vaporization

$$
E_{p}=\rho_{a} I^{-1} u^{*}\left(q_{s a t}\left(T_{g}\right)-q_{a}\right),
$$

where $\mathrm{I}^{-1}=\frac{k}{\ln \left(\frac{k \mathrm{u}^{*} \mathrm{z}_{\mathrm{a}}}{\mathrm{k}_{\mathrm{a}}}+\frac{\mathrm{z}_{\mathrm{a}}}{\mathrm{z}_{1}}\right)-\Psi_{\mathrm{h}}}$;

$\rho_{\mathrm{a}}$ is air density at the lowest model level; $k$ is the von Karman constant $(0.4) ; \mathrm{u}^{*}$ is friction velocity; $\mathrm{z}_{\mathrm{a}}$ is the height of the lowest model level; $Z_{l}$ is the depth of the molecular layer; $\Psi_{\mathrm{h}}$ is the nondimensional stability parameter based on the similarity theory; $q_{\text {sat }}\left(T_{g}\right)$ is the saturation mixing ratio at $T_{g} ; T_{g}$ is the skin or surface temperature; $q_{a}$ is the mixing ratio at the lowest model level; $\mathrm{k}_{\mathrm{a}}$ is the molecular diffusivity.

The estimation of surface ET by the bucket method is mainly affected by the relative magnitudes of

(1) $\rho_{a}$, referred to as term A hereafter; 


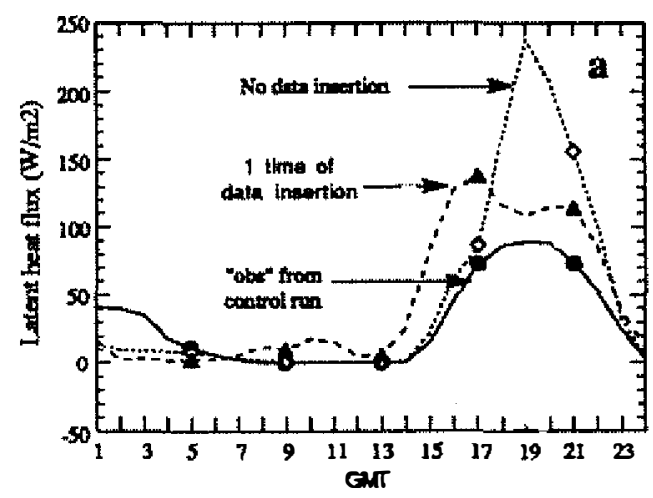

Fig. 3.3. The estimation of latent heat flux by the bucket method due to different simulated satellite data insertion rates: (a) for one time of data insertion, (b) for 7 times of data insertion, (c) for 13 times of data insertion during the updating or data assimilation period. Solid line is for simulated observation from the control run, dashed line for different simulation runs, and dotted line for normal model run without simulated satellite data insertion.
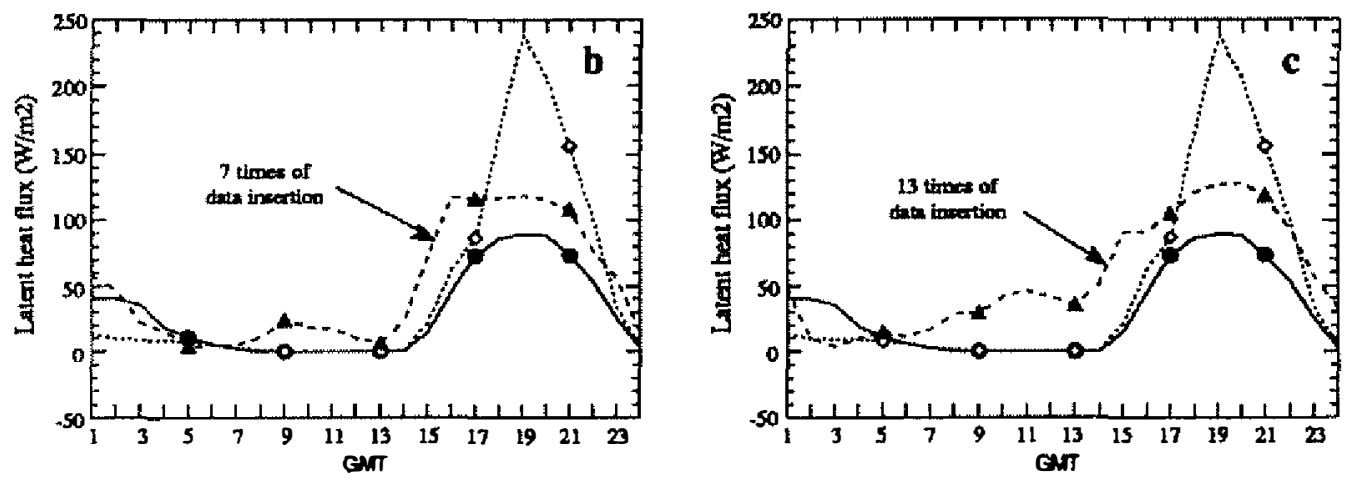

(2) $\mathrm{u}^{*}$, term $B$ hereafter;

(3) $\mathrm{I}^{-1}$, exchange coefficient, term $\mathrm{C}$ hereafter;

(4) $\mathrm{q}_{\text {sat }}\left(\mathrm{T}_{\mathrm{g}}\right)-\mathrm{q}_{\mathrm{a}}$, moisture gradient between the ground surface and lowest model level in the atmosphere, term $\mathrm{D}$ hereafter.

Of these, only term $\mathrm{D}$ is directly affected by the adjustment of surface temperature.

The following formula is used to detect the percentage of adjustment of these four terms owing to insertion of "satellite" temperature data during the data assimilation period.

$$
\frac{\mathrm{T}_{13}-\mathrm{T}_{0}}{\mathrm{~T}_{0}} \times 100 \% \text { or } \frac{\mathrm{T}_{07}-\mathrm{T}_{0}}{\mathrm{~T}_{0}} \times 100 \% \text {, etc. }
$$

where $\mathrm{T}$ can be term $\mathrm{A}, \mathrm{B}, \mathrm{C}$, or $\mathrm{D}$; the subscripts 0,13 , and 07 stand for 0,13 , and 7 times of data insertion, respectively.

In addition, an examination of the relative contribution (weight) of these four terms to the estimation of surface $\mathrm{ET}$ is made. $\mathrm{ET}$ is $\mathrm{L}_{\mathrm{v}} \mathrm{E}_{\mathrm{p}}$. If $\mathrm{ET}=\mathrm{A} \times \mathrm{B} \times \mathrm{C} \times \mathrm{D}$, then $\ln \mathrm{ET}=\ln \mathrm{A}+\ln \mathrm{B}$ $+\ln \mathrm{C}+\ln \mathrm{D}$ and,

$$
\frac{\mathrm{dET}}{\mathrm{ET}}=\frac{\mathrm{dA}}{\mathrm{A}}+\frac{\mathrm{dB}}{\mathrm{B}}+\frac{\mathrm{dC}}{\mathrm{C}}+\frac{\mathrm{dD}}{\mathrm{D}}
$$



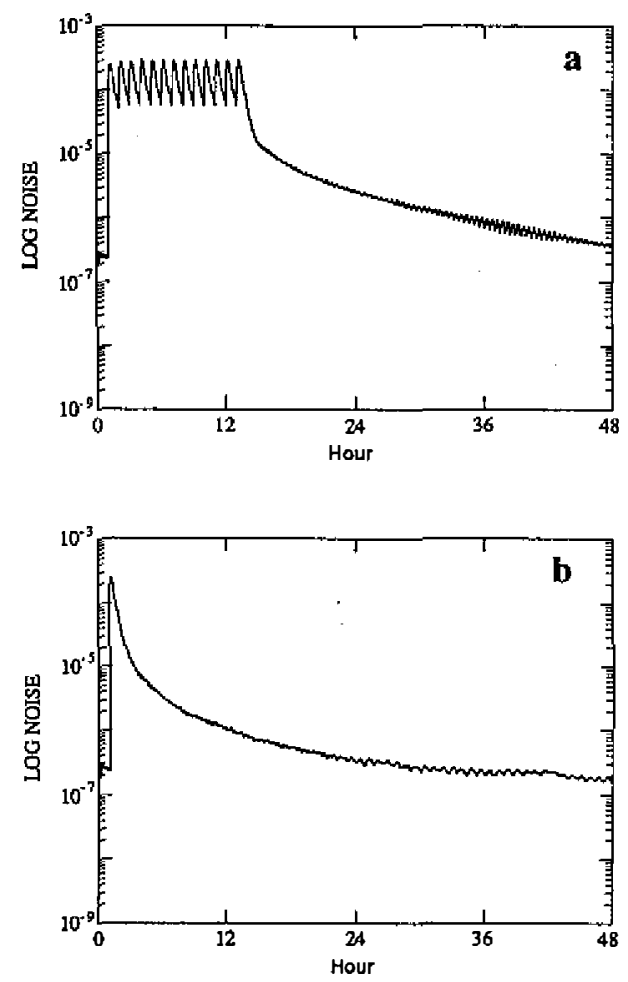

Fig. 3.4. Log of noise parameter (second time derivative of surface pressure) proposed by Bleck (1977) versus time (hours) average over model's computational domain for (a) 13 times of data insertion, (b) 1 time of data insertion during the data assimilation period.

The change in ET is due to changes in A, B, C, and D. Changes in A, B, C, and D are either directly or indirectly due to the adjustment of temperature. The relative weight of $A$ that contributes to the calculation of ET can be measured by

$$
\text { Contribution of } A=\frac{\left|\frac{\mathrm{dA}}{\mathrm{A}}\right|}{\left|\frac{\mathrm{dA}}{\mathrm{A}}\right|+\left|\frac{\mathrm{dB}}{\mathrm{B}}\right|+\left|\frac{\mathrm{dC}}{\mathrm{C}}\right|+\left|\frac{\mathrm{dD}}{\mathrm{D}}\right|} \times 100 \%
$$

The adjustments of A, B, C, and D and their relative contributions to the calculation of surface ET during the data assimilation period due to "satellite" temperature data insertion are thus evaluated.

It turns out that the adjustment of term $A$ is always less than $5 \%$ and it is therefore neglected. The mean percentage of adjustment of $\mathrm{B}, \mathrm{C}$ and $\mathrm{D}, \mathrm{q}_{\mathrm{sat}}\left(\mathrm{T}_{\mathrm{g}}\right)$ and $\mathrm{q}_{\mathrm{sat}}\left(\mathrm{T}_{\mathrm{a}}\right)$ during the data assimilation period versus different data insertion rates is shown in Fig. 3.5a. This figure shows that the $\mathrm{B}$ and $\mathrm{C}$ terms increased in value after adjustment, i.e., positive adjustment, while the $\mathrm{D}$ term decreased. It can be seen, from Fig. 3.5b, that friction velocity and surface moisture gradient dominate the contributions to the surface ET estimated by the model. Greater friction velocity means a rougher surface. This means a greater possibility for small scale eddies (turbulence) to generate, and subsequently more surface moisture is able to evaporate into the air. In addition, a greater surface gradient means more moisture in the soil can get into the 

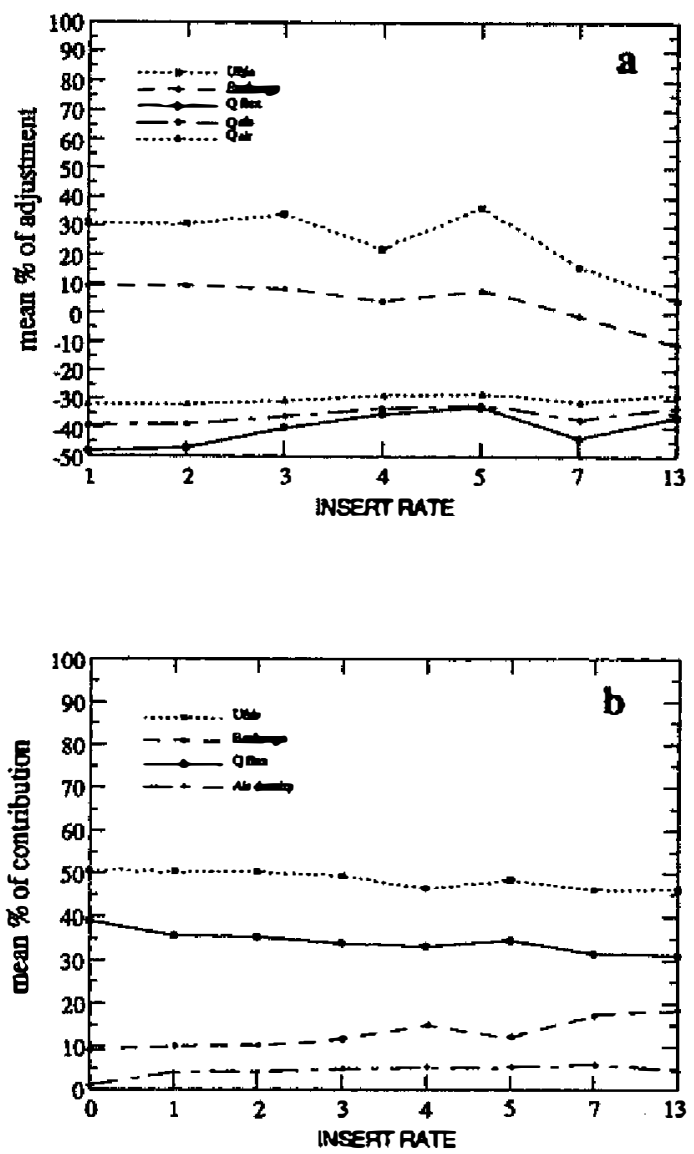

Fig. 3.5. The mean percentage of (a) adjustment (b) contribution (to the estimation of latent heat flux) of friction velocity (Ufric, dotted line with square), exchange coefficient (Exchange, short dashed line), moisture gradient between ground surface and the lowest model level (Qflux, solid line), saturation mixing ratio at the ground surface (Qsfe, long dashed line), mixing ratio at the lowest model level (Qair, dotted line with triangle), and air density at the lowest model level (Air density, long dashed line), with respect to different simulated satellite temperature data insertion rates during the updating period.

surface layer. As the data insertion rate increases, the amount of adjustment of B and C tends to decrease, and there is less adjustment of $\mathrm{D}$. The mean relative percentage of contribution to ET by A, B, C and D versus different data insertion rates is shown in Fig. 3.5b. Higher insertion rates lead to a slight decrease in the contribution from $\mathrm{B}$ and $\mathrm{D}$, while the contribution from $C$ increases from $10 \%$ for 2 data insertions to $20 \%$ for 13 data insertions.

It is therefore known that the insertion of simulated satellite temperature data will reduce the moisture gradient between the ground surface and lowest model level. Meanwhile the mean relative contributions to ET by A, B, C and D do not vary much. A decrease in moisture gradient between the ground surface and lowest model level will then lead to a decrease of potential ET, i.e., less moisture is available in the ground to evaporate. Thus, the M100 decreases its degree of overestimation of surface ET after the data assimilation cycle.

Time series of percentage adjustment of A, B, C and D, and their relative contribution to ET, during the data assimilation period for 7 and 13 data insertions, are shown in Fig. 3.6a and $\mathrm{b}$, respectively. It is observed that 7 data insertions causes more obvious oscillation of friction velocity and moisture flux than 13 data insertions. The mean percentage adjustment of $\mathrm{B}, \mathrm{C}$ and $\mathrm{D}$, and their mean relative contributions to ET for 7 and 13 data insertions, are listed in Table 3.2. In both cases, the relative con ributions to ET of B, C and D are similar. A rate of 7 
data insertions causes a smaller adjustment of B and C and a larger decrease in D. Thus, compared to 7 times of data insertion, 13 times of data insertion generates a worse estimation of surface ET after the data assimilation cycle (Table 3.1).

In summary, during the data assimilation cycle, the contributions of ET due to air density of the lowest model level $\left(\rho_{a}\right)$, friction velocity $\left(u^{*}\right)$, and exchange coefficient $\left(I^{-1}\right)$ are not dramatically adjusted (Fig. 3.5b) as a result of "satellite" data insertion, whereas a significant decrease (30-40\%) in moisture gradient between the ground surface and lowest model level $\left[q_{\text {sat }}\left(T_{\mathrm{g}}\right)-\mathrm{q}_{\mathrm{a}}\right]$ is observed due to an effective decrease in the skin temperature resulting from "satellite" data insertion. The potential ET estimated by the bucket method is thus greatly reduced during the data assimilation period, and a weaker surface ET in the model therefore occurs in the succeeding simulation period.

It is thus concluded that Gal-Chen's variational FDDA technique of assimilating satellite measurements is able to improve the model's estimation of surface ET. Even if there is only one insertion of "satellite" data, the bucket method will make a better estimation of daytime surface ET, owing to a significant reduction of potential ET because of a pronounced decrease
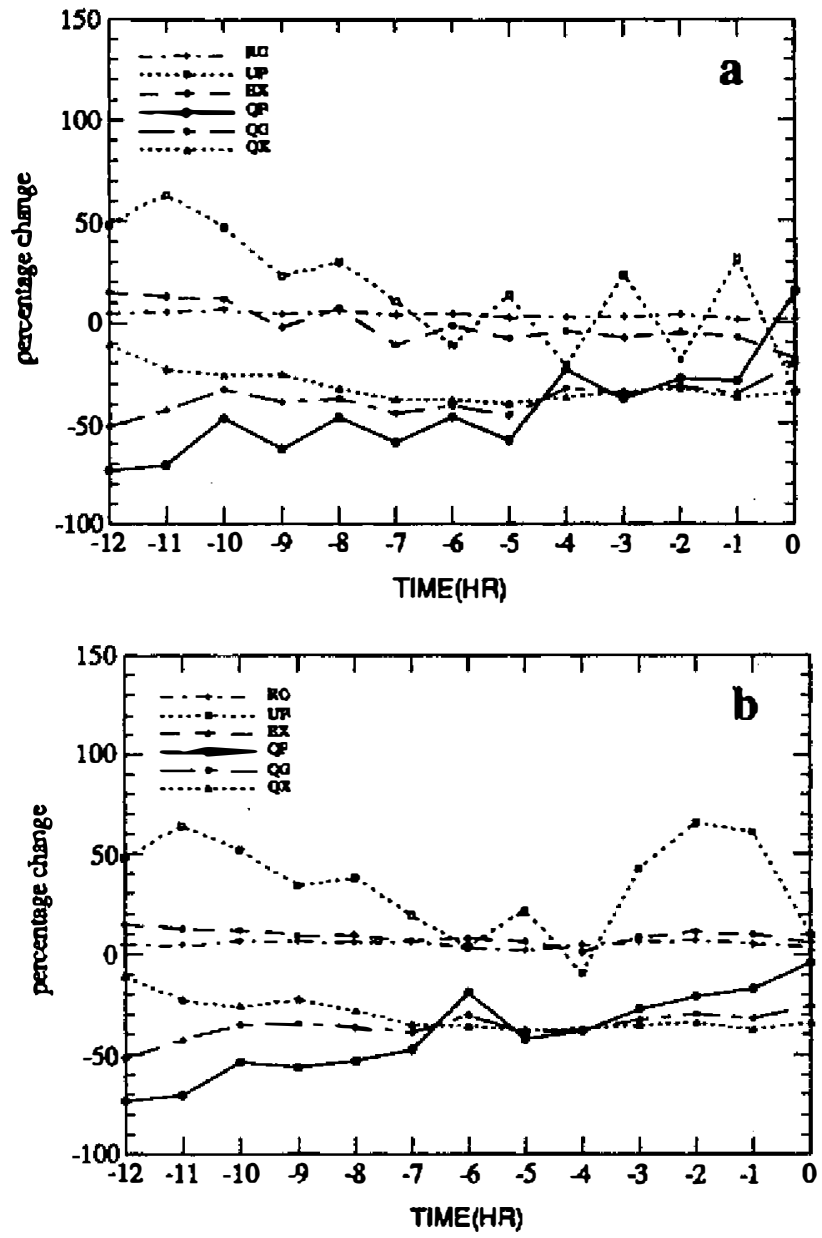

Fig. 3.6. Time series of adjustment of air density at the lowest model level (RO, short dashed line), friction velocity (UF, dotted line with square), exchange coefficient (EX, dashed line with smaller solid circle), moisture gradient between ground surface and the lowest model level (QF, solid line with bigger solid circle), saturation mixing ratio at the ground surface ( $Q G$, long dashed line with smaller solid circle), and mixing ratio at the lowest model level (QX, dotted line with triangle), for different numbers of simulated satellite insertions during the data assimilation period. (a) for 7 times of data insertion, (b) for 13 times of data insertion. 
Table 3.2. The mean percentage adjustment of friction velocity (term $B$ in the text), exchange coefficient (term C), moisture gradient (term D), and their mean relative contributions to model's (using the bucket method) estimation surface ET, during the data assimilation period, for 7 and 13 simulated satellite data insertions.

\begin{tabular}{lcccccc} 
& \multicolumn{2}{c}{$\mathrm{B}$ (friction velocity) } & \multicolumn{2}{c}{$\mathrm{C}$ (exchange coeff) } & \multicolumn{2}{c}{$\mathrm{D}$ (moisture gradient) } \\
$\begin{array}{l}\text { insertion rate } \\
\text { mean \% of }\end{array}$ & +15.69 & +36.55 & -1.51 & +7.61 & -43.66 & -32.85 \\
$\begin{array}{l}\text { medjustment } \\
\begin{array}{l}\text { mean \% of } \\
\text { contribution }\end{array}\end{array}$ & 45.84 & 48.42 & 16.97 & 11.80 & 31.64 & 34.73 \\
& & & & & &
\end{tabular}

in skin temperature and the associated moisture content in the model's ground surface.

The formulation of the PM method derived in CL97 for the MM4 system is as follows:

$$
\mathrm{L}_{\mathrm{v}} \mathrm{E}_{\mathrm{p}}=\frac{\left[(1-\alpha) \mathrm{S} \downarrow+\mathrm{L}_{\mathrm{w}} \downarrow-\varepsilon_{\mathrm{g}} \sigma \mathrm{T}_{\mathrm{a}}^{4}-\mathrm{H}_{\mathrm{m}}\right] \Delta+(1+\gamma) \mathrm{L}_{\mathrm{v}} \mathrm{E}_{\mathrm{a}}}{\Delta+(1+\gamma)\left(1+\mathrm{I}^{-1} \mathrm{r}_{\mathrm{s}}\right)},
$$

where

$$
\begin{aligned}
& \Delta=\frac{\mathrm{L}_{\mathrm{v}}}{\mathrm{c}_{\mathrm{pm}}} \cdot\left(\frac{\mathrm{dq}_{\mathrm{sat}}}{\mathrm{dT}}\right)_{\mathrm{T}_{\mathrm{a}}} \cdot \frac{\ln \frac{\mathrm{z}_{\mathrm{a}}}{\mathrm{z}_{\mathrm{o}}}-\psi_{\mathrm{h}}}{\ln \left(\frac{k \mathrm{u} * \mathrm{z}_{\mathrm{a}}}{\mathrm{k}_{\mathrm{a}}}+\frac{\mathrm{z}_{\mathrm{a}}}{\mathrm{z}_{l}}\right)-\psi_{\mathrm{h}}} \cdot\left(\frac{100}{\mathrm{p}_{\mathrm{sfc}}}\right)^{\frac{\mathrm{R}}{\mathrm{C}_{\mathrm{p}}}} \text { and } \\
& \gamma=\frac{4 \varepsilon_{\mathrm{g}} \sigma \mathrm{T}_{\mathrm{a}}^{3}}{\mathrm{c}_{\mathrm{pm}} \rho_{\mathrm{a}} k \mathrm{u} *\left(100 / \mathrm{p}_{\mathrm{sfc}}\right)^{\left.\mathrm{R} / \mathrm{c}_{\mathrm{p}} / \ln \frac{\mathrm{z}_{\mathrm{a}}}{\mathrm{z}_{\mathrm{o}}}-\psi_{\mathrm{h}}\right)}},
\end{aligned}
$$

with $\mathrm{E}_{\mathrm{a}}=\rho_{\mathrm{a}} \mathrm{I}^{-1}\left[\mathrm{q}_{\mathrm{sat}}\left(\mathrm{T}_{\mathrm{a}}\right)-\mathrm{q}_{\mathrm{a}}\right]$.

$\mathrm{H}_{\mathrm{m}}$ is the ground heat flux (heat flow into the substrate); $\mathrm{H}_{\mathrm{s}}$ is the sensible heat flux; $\alpha$ is the albedo; $\mathrm{S}$ is the solar constant, so $(1-\alpha) \mathrm{S} \downarrow$ is the net shortwave radiative flux; $\mathrm{L}_{\mathrm{w}} \downarrow$ is the downward longwave radiative flux; $\varepsilon_{\mathrm{g}}$ is the emissivity of the ground surface; $\sigma$ is the StefanBoitzmann constant; $c_{p m}$ is specific heat at constant pressure for moist air; $T_{a}$ is temperature of the lowest model level; $q_{s a t}\left(T_{a}\right)$ is the saturation mixing ratio at $T_{a} ; R$ is the gas constant for dry air; $\mathrm{p}_{\mathrm{sic}}$ is the surface pressure; and the stomatal resistance $\mathrm{r}_{\mathrm{s}}$ (as defined by the resistance under no water stress) is set at $90 \mathrm{sm}^{-1}$ (following Monteith 1965; Pan 1990; and Pan et al. 1996).

Similar OSSEs using the PM method are also conducted and the results show that the assimilation of "satellite" data improves the model's estimation of surface ET as well. A similar diagnostic procedure for the PM method is executed to evaluate the main factors leading to the improvement. It is shown that the key factors leading to an improvement in the model's 
estimating. LHF are that:

1) temperature at the lowest model level $\left(\mathrm{T}_{\mathrm{a}}\right)$ is decreased; and

2) $\mathrm{E}_{\mathrm{a}}$ is decreased, by reason of a reduction of mixing ratio depression $\left[\mathrm{q}_{\mathrm{sat}}\left(\mathrm{T}_{\mathrm{a}}\right)-\mathrm{q}_{\mathrm{a}}\right]$ at the lowest model level during the data assimilation period.

The assimilation of "satellite" data reduces the potential ET as a result of a decrease of T and the associated mixing ratio depression at the lowest model level during the data assimilation period. Thus, a more reasonable estimation of LHF by the model using the PM method is foreseeable after the data assimilation period.

\section{REAL GOES DATA ASSIMILATION EXPERIMENTS}

Several GOES retrieved temperature data sets in different seasons of 1995 are obtained from the National Environmental Satellite, Data, and Information Services (NESDIS) to conduct real data assimilations. A similar updating procedure to the OSSEs is applied in the real GOES data assimilation experiments. Some characteristics of the GOES retrieved temperature and moisture data are listed as follows.

a) The VAS instruments on GOES-6 and GOES-7 were replaced with a set of continuously operating sounders on GOES-8 and GOES-9 in late 1994, and 1995.

b) The raw radiance data is archived once per hour with 18 channels. Thus, there are temperature and moisture data at 18 different height levels covering continental U.S. (Menzel and Purdom 1994).

c) The horizontal resolution of raw radiance data is about $10 \times 10 \mathrm{~km}$. Retrieved profiles (temperatures and dewpoint temperatures) are routinely made every three hours and on $50 \times 50$ $\mathrm{km}$ grid.

d) The retrieval techniques were developed by NESDIS (Hayden et al. 1996).

It needs to be stated that the dates of GOES retrievals used in real data assimilation are days on which both the observations from the SGP ARM site and the modeI showed no rainfall event in the same area. There are two principal reasons for making this kind of selection. First, such a selection can give some clear indication of systematic differences in the diumal cycle between model forecasts (due to the GOES data insertion) and observational data. The incoming shortwave and longwave radiation and outgoing longwave radiation from the ground surface would be reflected, absorbed or interfered by rain clouds. Surface energy balance processes, such as the partitioning between net radiation at the ground surface, LHF and SHF, would be altered by the existence of rain clouds or excessive cloudiness. Thus, the reasoning which leads to a proper explanation of why the model's performance is improved or not by insertion of the GOES data, would no longer be straightforward if there were excessive cloudiness or rain clouds over the SGP ARM site. Second, whether there are rain clouds or excessive cloudiness over the SGP ARM site and the adjacent areas needs to be known. Then it is impossible to make sounding retrievals according to the GOES sounder observations (Hayden et al. 1996). Data-void pockets will then appear. The use of the GOES data with too many data-sparse areas would produce excessive model noise and might lead to worse model simulations owing to mismatched gradients in the model (Cram and Kaplan 1985). 


\subsection{Experiment Designs of Assimilating GOES Retrievals}

The model with a grid distance of $100 \mathrm{~km}$ always starts at $00 \mathrm{Z}$ of a particular date. The real GOES data assimilation period (DAP) lasts for $12 \mathrm{hrs}$ until $12 \mathrm{Z}$. The procedure of the FDDA experiments is the same as that stated in subsection 3.1. The DAP is followed by $60 \mathrm{hrs}$ of simulation/forecast period. The normal model run without GOES data insertion is denoted as 0GSP. Five different ways of assimilating GOES data are as follows.

(1) Static initialization (denoted as 1GSP, hereafter). The GOES data are incorporated into the temperature data in the initial condition file for the model to start its integration.

(2) Static initialization plus assimilation of all the available GOES data during the $12 \mathrm{hr}$ DAP: 5GSP if the GOES data at 00Z, 03Z, 06Z, 09Z, and $12 \mathrm{Z}$ are all available; or 4GSP if the GOES data at $00 \mathrm{Z}, 03 \mathrm{Z}, 09 \mathrm{Z}$, and $12 \mathrm{Z}$ are available, etc.

(3) Static initialization plus assimilation of the GOES data at $12 Z$ only (2GSP).

(4) Static initialization plus nudging the model's temperature field toward the temperature field at $12 Z$, in which vertically averaged temperatures from the GOES data have replaced the model-generated vertically averaged temperatures (Ng2GSP). The nudging coefficient is set to 0.0006 (Anthes et al. 1987) during the DAP. The procedure for this kind of experiment is illustrated in Fig. 4.1a.

(5) Static initialization plus nudging the model's temperature field toward all the available temperature fields at $03 \mathrm{Z}, 06 \mathrm{Z}, 09 \mathrm{Z}$, and $12 \mathrm{Z}$, in which vertically averaged temperatures from the GOES data have replaced the model-generated vertically averaged temperatures (Ng5GSP or Ng4GSP, etc., Fig. 4.1b).

The purpose of these experiments is to examine (i) the impact of the GOES data on the model performance, (ii) whether more real GOES data insertion results in better model performance, and (iii) whether the proposed nudging technique can enhance the advantages of GalChen's FDDA technique.

Quantities of interest, such as the skin temperature, LHF, SHF, $R_{\text {net }}, T_{a}, q_{a}, q_{\text {sat }}\left(T_{g}\right)$ and $q_{\text {sat }}$ $\left(\mathrm{T}_{\mathrm{a}}\right)$, are output at each time step $(2.5 \mathrm{~min})$. The hourly averages of the model output on a model grid closest to the 3 observation stations in the SGP ARM site are compared to the corresponding observational data set. In the following discussion, the variations of surface fluxes, temperature and moisture for the daytime are mentioned more frequently than those at night since error in these surface fluxes during the daytime can penetrate over deep layers, and therefore affect the synoptic pressure fields (Beljaars et al. 1996). The daytime is defined as $13 Z$ to $24 Z$, or 07 to 10 local standard time at the SGP ARM site.

It should be noted that in the following discussions " $1-24 \mathrm{hr}$ forecast period" refers to the period which includes the $12 \mathrm{hr}$ DAP and the following first $12 \mathrm{hr}$ of the simulation period; " $25-48 \mathrm{hr}$ forecast period" means the period that is $13-36 \mathrm{hr}$ after the DAP; and " $49-72 \mathrm{hr}$ forecast period" is the final $24 \mathrm{hr}$ interval of the simulation period. Since the model always starts its integration at $00 \mathrm{Z}$, with this way of separating the forecast periods, it will be very convenient to show the diurnal cycle of LHF and SHF, etc., in each Forecast Period (FP). The comparison of surface fluxes, temperature, and mixing ratio, and their diurnal variations revealed by various FDDA experiments, can be easily made. 


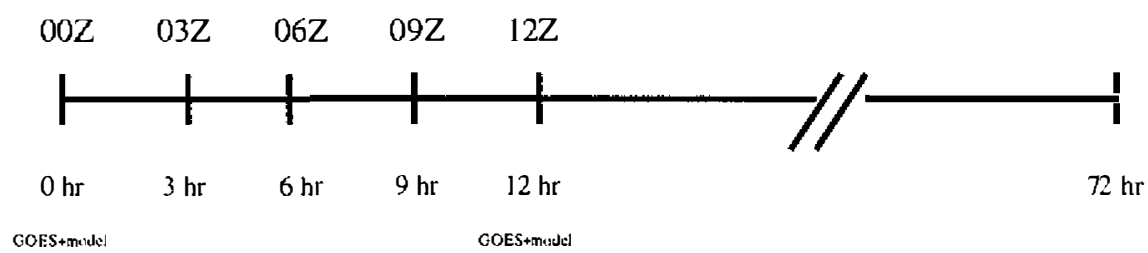

(a)

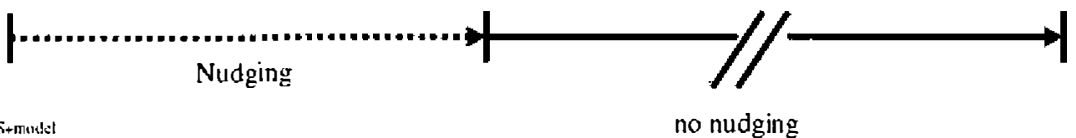

(b)

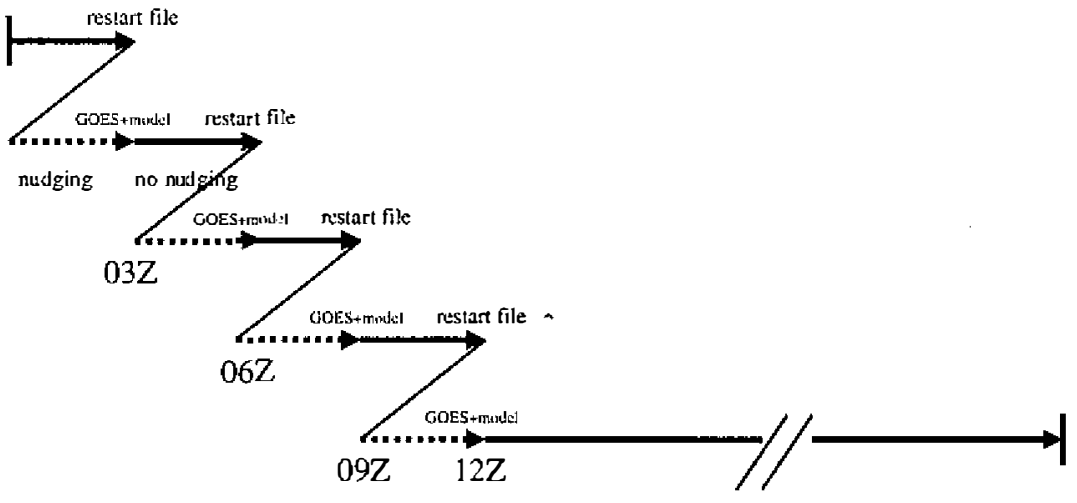

Fig. 4.1. Time line showing the process of nudging technique used in real GOES data assimilation experiment. (a) Nudging the model's temperature toward the mixture of GOES temperature data and model-generated temperature field at 12Z; and (b) nudging the model's temperature toward the mixture of all available GOES temperature data and model-generated temperature field at 03Z, 06Z, 09Z, and 12Z. Dashed lines stand for nudging technique being applied, and solid lines for no nudging technique. "GOES+model" means the vertically averaged temperature for the bottom and top halves of the atmosphere in the restart file for the model are replaced by those from the GOES temperature data.

\subsection{Assimilation of the GOES Temperature Data from October 16, 1995}

The GOES sounding locations at $00 \mathrm{Z}, 03 \mathrm{Z}, 09 \mathrm{Z}$, and $12 \mathrm{Z}$ (data at $06 \mathrm{Z}$ is missing) on October 16, 1995 are shown in Fig. 4.2. Although the GOES sounding density varies much with time, the GOES data remains influential in all the following experiments owing to the application of the Cressman scheme, in which the model's temperature fields are used as a background information (Gal-Chen et al. 1986). The domains of the mean vertical temperature differences between the GOES data and the model-generated data for the bottom and top halves of the atmosphere at $00 \mathrm{Z}$ and $12 \mathrm{Z}$ are illustrated in Fig. 4.3. It can be seen from Fig. 4. 3 that the bottom half of the mean vertical GOES temperature field is colder than the corresponding model-generated mean vertical temperature field in the central U. S., whereas, the 

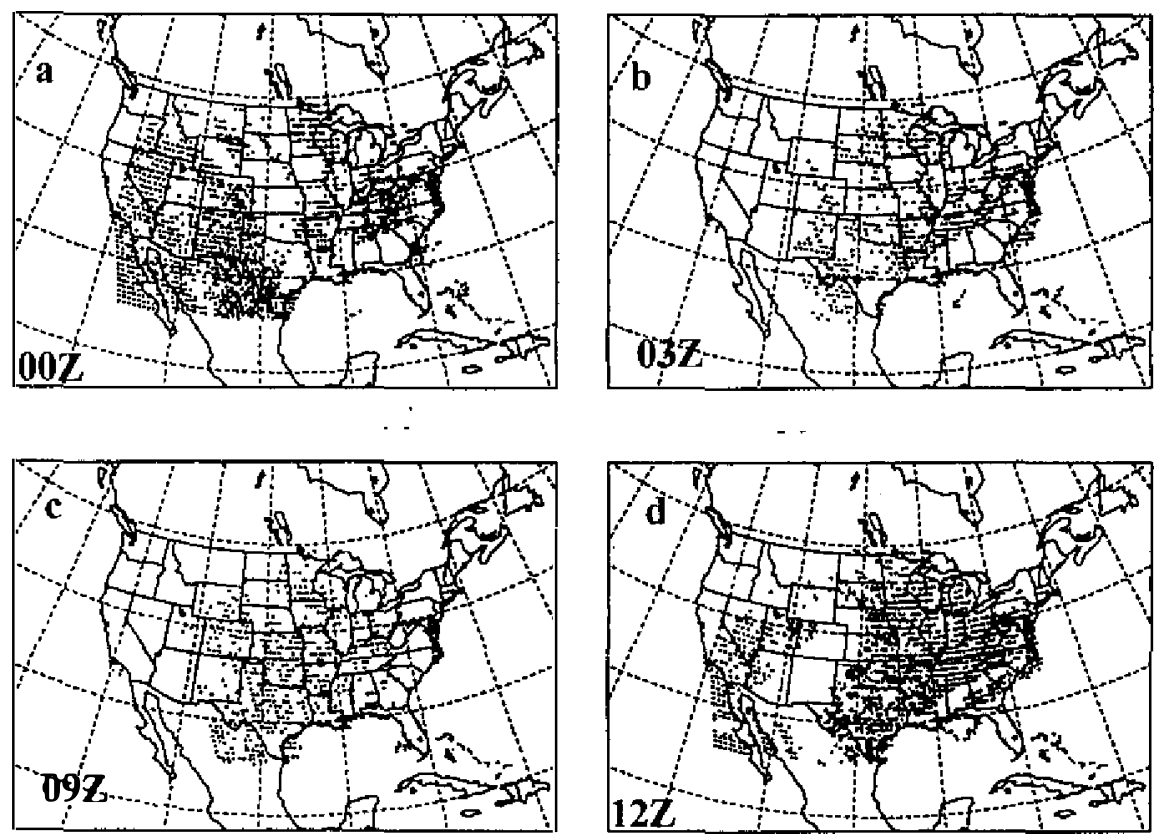

Fig. 4.2. Distribution of GOES sounding locations valid at (a) 00Z, (b) 03Z, (c) 09Z, and (d) 12Z, October 16, 1995.

top half of the mean vertical GOES temperature field is warmer than the corresponding modelgenerated mean vertical temperature field.

The daytime RMS errors of the model simulation of LHF from different FDDA experiments are illustrated in Fig. 4.4. Mean values of $\mathrm{T}_{g}\left({ }^{\circ} \mathrm{C}\right), \mathrm{T}_{\mathrm{a}}\left({ }^{\circ} \mathrm{C}\right)$ which is $40 \mathrm{~m}$ above ground level at the SGP ARM site, $\mathrm{q}_{\text {sat }}\left(\mathrm{T}_{\mathrm{g}}\right)$ in $\mathrm{g} / \mathrm{kg}, \mathrm{q}_{\text {sat }}\left(\mathrm{T}_{\mathrm{g}}\right)-\mathrm{q}_{\mathrm{a}}, \mathrm{q}_{\text {sat }}\left(\mathrm{T}_{\mathrm{a}}\right)-\mathrm{q}_{\mathrm{a}}$, and the percentage changes of $\mathrm{q}_{\text {sat }}\left(\mathrm{T}_{\mathrm{g}}\right)-\mathrm{q}_{\mathrm{a}}$ or $\mathrm{q}_{\mathrm{sat}}\left(\mathrm{T}_{\mathrm{a}}\right)-\mathrm{q}_{\mathrm{a}}$ relative to 0GSP from various FDDA experiments during the DAP are listed in Table 4.1, because the adjustment of these quantities are crucial factors for the model to make more reasonable estimation of surface ET, as discussed in the OSSEs.

As can be seen from Fig. 4.4, most of the time the GOES data insertion indeed cast a positive impact on the model's prediction of daytime LHF $12 \mathrm{hr}$ after the DAP, but only minor improvement in the estimation of LHF by the PM method $36 \mathrm{hr}$ after the DAP. One also notices that a higher frequency of GOES data insertion does not necessarily result in a more accurate estimation of daytime LHF (Fig. $4.4 \mathrm{a}$ vs. Fig. 4.4c).

\subsubsection{For the bucket method}

It is observed from Fig. 4.4a that static initialization (1GSP) with the bucket method gives a better estimation of daytime LHF than the 2GSP and 4GSP in all the FPs. The inclusion of GOES data from 4 time periods (4GSP) allows the model with the bucket method (hereafter, $\mathrm{MBK}$ ) to make a significant improvement in estimating daytime LHF following the DAP (FP of 12-24 hr), and a minor improvement during the 49-72 hr FP, when compared to the 0GSP 

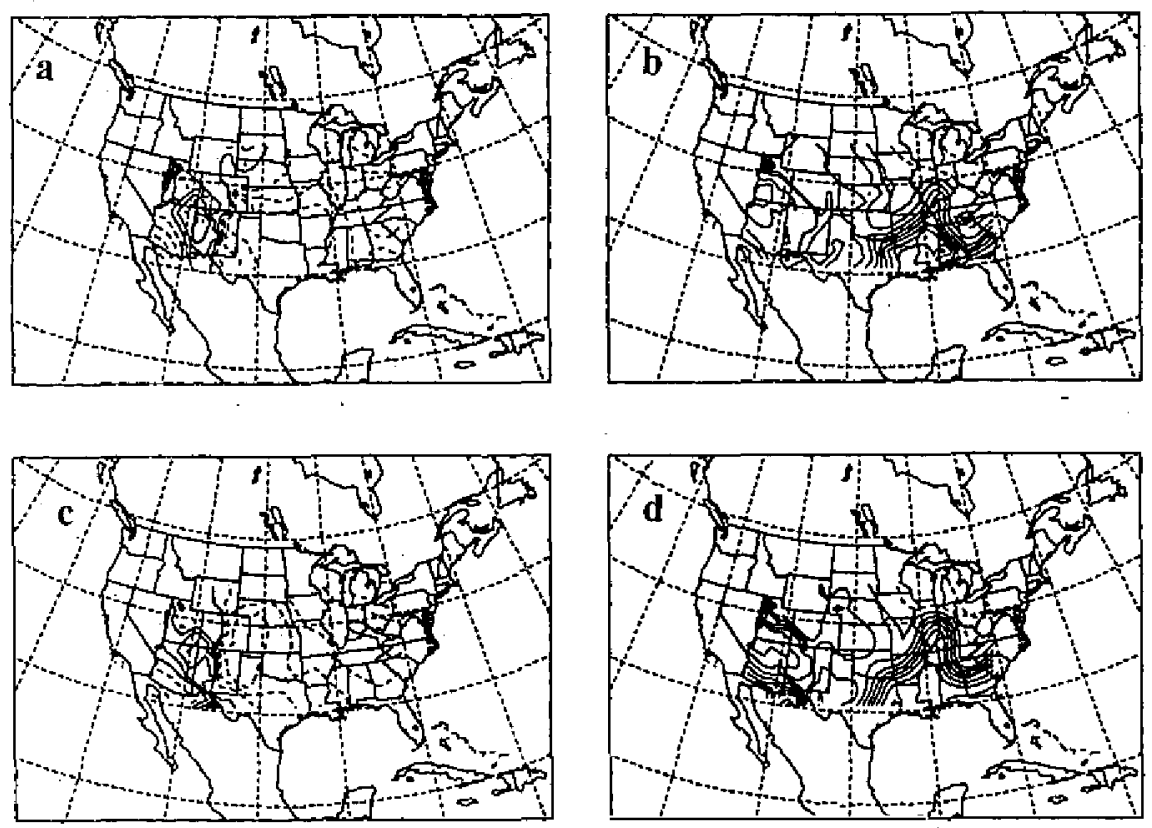

Fig. 4.3. Vertically averaged temperature differences between GOES and modelgenerated data of (a) bottom half (surface to $500 \mathrm{mb}$ ) of the atmosphere at $00 \mathrm{Z}$; (b) top half (500 to $50 \mathrm{mb}$ ) of the atmosphere at 00Z; (c) bottom half of the atmosphere at $12 Z$; and (d) top half of the atmosphere at $12 Z$, October 16, 1995. Area shown is the assimilation domain. Solid contours stand for positive values, dashed contours for negative values. The contour interval is $0.1^{\circ} \mathrm{K}$.

(Fig. 4.4c). This improvement is mainly due to a significant reduction of mean $\mathrm{T}_{\mathrm{g}}$ and $\mathrm{q}_{\mathrm{sat}}\left(\mathrm{T}_{\mathrm{g}}\right)$ $\mathrm{q}_{\mathrm{a}}$ during the DAP. In comparison with the 0GSP, the 4GSP shows a decrease in the mean $\mathrm{T}_{\mathrm{g}}$ from 14.74 to $12.23{ }^{\circ} \mathrm{C}$ and a $29 \%$ reduction of $\mathrm{q}_{\text {sut }}\left(\mathrm{T}_{\mathrm{g}}\right)-\mathrm{q}_{\mathrm{a}}$ from 5.60 to $3.97 \mathrm{~g} / \mathrm{kg}$ (Table $4.1 \mathrm{a} 1$ vs. Table 4.1a4), such that the MBK has a higher probability of making a more accurate estimation of daytime LHF during the simulation period. It is noted that the 4GSP with the bucket method shows a poorer estimation of daytime LHF during the 25-48 hr FP (Fig. 4.4c) due to an inappropriate prediction of skin temperature and the associated $\mathrm{q}_{\mathrm{sat}}\left(\mathrm{T}_{\mathrm{g}}\right)-\mathrm{q}_{\mathrm{a}}$. During the 25-48 hr FP, mean $\mathrm{T}_{\mathrm{g}}$ and $\mathrm{q}_{\mathrm{sat}}\left(\mathrm{T}_{\mathrm{g}}\right)-\mathrm{q}_{\mathrm{a}}$ from the $0 \mathrm{GSP}$ with the bucket method are $18.6^{\circ} \mathrm{C}$, and $2.62 \mathrm{~g} /$ $\mathrm{kg}$, respectively. In the same time period, the 4GSP with the bucket method results in an increase in mean $\mathrm{T}_{\mathrm{g}}$ and $\mathrm{q}_{\mathrm{sat}}\left(\mathrm{T}_{\mathrm{g}}\right)-\mathrm{q}_{\mathrm{a}}$ to $18.7^{\circ} \mathrm{C}$ and $5.32 \mathrm{~g} / \mathrm{kg}$, respectively. That is, the moisture content at the ground surface increases in the 4GSP such that the MBK generates a poorer estimation of the LHF during the FP of $25-48 \mathrm{hr}$. The same reason holds for the poorer estimation of the LHF for the 2GSP (Fig. 4.4b).

Nudging the model's temperature toward the GOES data at $12 \mathrm{Z}$ leads to a great improvement in the ability of the MBK to estimate daytime LHF during the entire simulation period 

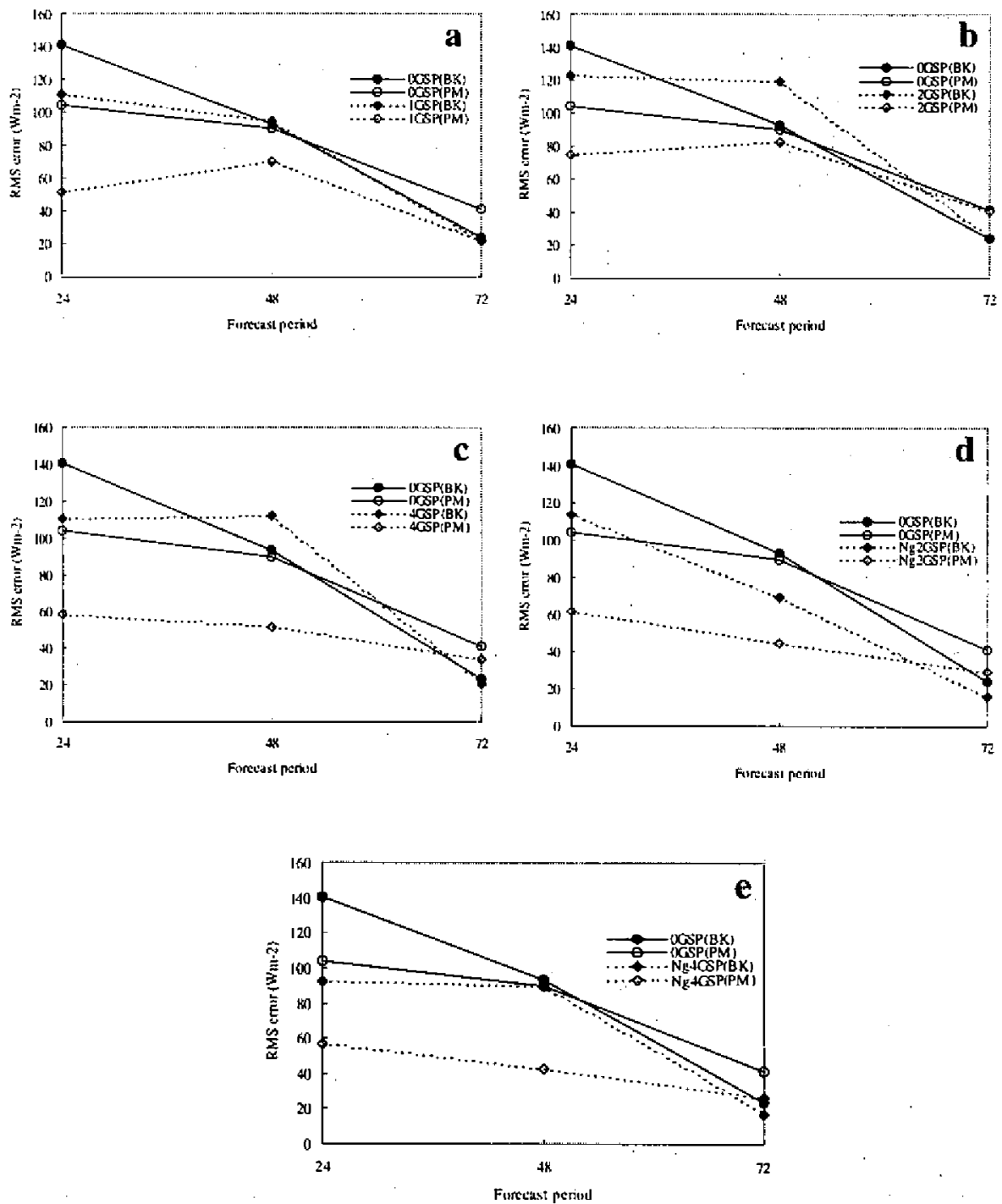

Fig. 4.4. Daytime (12Z to $24 Z$ ) root mean square errors of latent heat flux in model's 1-24 hr, 25-48 hr, and 49-72 hr forecast periods (denoted in the figs. as 24,48 , and 72 , respectively, ) from different FDDA experiments using the GOES data from October 16, 1995. In these figures, solid line with solid circle is for the normal model run without GOES data insertion (OGSP) with the bucket (BK) method; solid line with open circle is for OGSP with the PM method. (a) dotted line with solid diamond is for 1GSP with bucket method, dotted line with open diamond is for 1GSP with the PM method; (b) similar to (a) but for 2GSP; (c) similar to (a) but for 4GSP; and (d) similar to (a) but for Ng2GSP, (e) similar to (a) but for $\mathrm{Ng} 4 \mathrm{GSP}$. 
Table 4.1. Mean values of skin temperature $\left(\mathrm{T}_{\mathrm{g}}\right.$ in $\left.{ }^{\circ} \mathrm{C}\right)$, saturation mixing ratio at the ground surface $\left[\mathrm{q}_{\mathrm{sat}}\left(\mathrm{T}_{\mathrm{g}}\right)\right.$ in $\left.\mathrm{g} / \mathrm{kg}\right]$ and saturation mixing ratio at the lowest model level $\left[\mathrm{q}_{\mathrm{sat}}\left(\mathrm{T}_{\mathrm{a}}\right)\right]$, moisture gradient between the ground surface and the lowest model level $\left[\mathrm{q}_{\mathrm{sat}}\left(\mathrm{T}_{\mathrm{g}}\right)-\mathrm{q}_{\mathrm{a}}\right]$, mixing ratio depression $\left[\mathrm{q}_{\mathrm{sat}}\left(\mathrm{T}_{\mathrm{a}}\right)-\mathrm{q}_{\mathrm{a}}\right]$ and temperature at the lowest model level $\left(\mathrm{T}_{\mathrm{a}}\right.$ in $\left.{ }^{\circ} \mathrm{C}\right)$ during the data assimilation period (DAP) of different FDDA experiments. The " $\%$ change" in the table stands for the percentage change of $\mathrm{q}_{\text {sat }}\left(\mathrm{T}_{\mathrm{g}}\right)-\mathrm{q}_{\mathrm{a}}$ for the bucket method or $\mathrm{q}_{\mathrm{sat}}\left(\mathrm{T}_{\mathrm{g}}\right)-\mathrm{q}_{\mathrm{a}}$ for the PM method relative to 0 GSP for different FDDA experiments. The GOES data used for data assimilation are from 16 October 1995.

(a) For bucket method

\begin{tabular}{|c|c|c|c|c|c|}
\hline & $\mathrm{T}_{\mathrm{g}}$ & $T_{a}$ & $\mathrm{q}_{\mathrm{sal}}\left(\mathrm{T}_{\mathrm{g}}\right)$ & $\mathrm{q}_{\mathrm{sat}}\left(\mathrm{T}_{\mathrm{g}}\right)-\mathrm{q}_{\mathrm{a}}$ & $\%$ change \\
\hline Observation & 13.52 & 18.76 & 10.09 & 4.84 & \\
\hline at 0 GSP & 1474 & 2521 & 1093 & 5.60 & \\
\hline a2 1GSP & 13.76 & 20.67 & 10.20 & 4.39 & -21.6 \\
\hline $2 \mathrm{gsp}$ & 1368 & 2058 & 1014 & 434 & 422.5 \\
\hline a4 4GSP & 12.23 & 19.13 & 9.89 & 3.97 & -29.1 \\
\hline $\mathrm{as}^{2} \mathrm{Ng} 2 \mathrm{gP}$ & $13 \%$ & $15 \%$ & 996 & -394 & \\
\hline a6 Ng4GSP & 13.04 & 15.68 & 9.79 & 3.36 & -40.0 \\
\hline
\end{tabular}

(b) For PM method

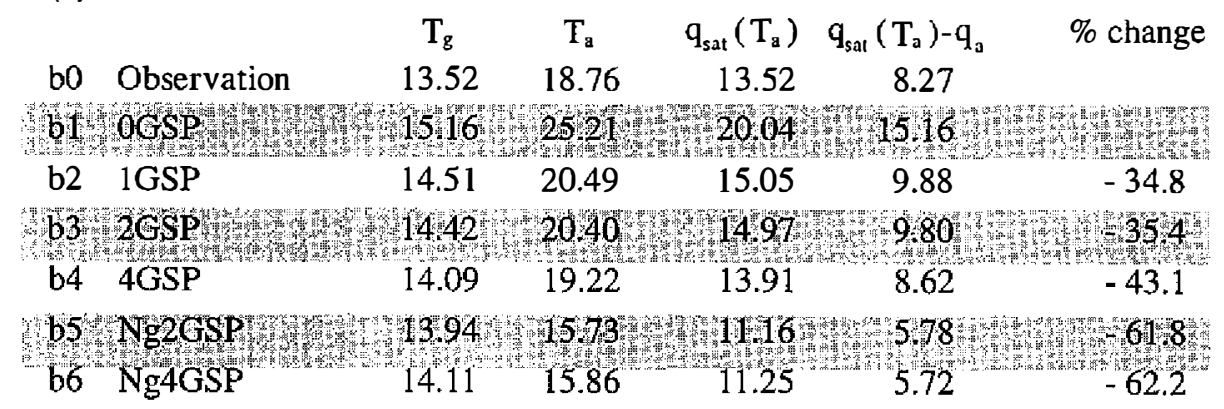

(Fig. 4.4d). The Ng2GSP results in a mean $\mathrm{T}_{\mathrm{g}}$ and $\mathrm{q}_{\mathrm{sat}}\left(\mathrm{T}_{\mathrm{g}}\right)-\mathrm{q}_{\mathrm{a}}$ of $13.30^{\circ} \mathrm{C}$ and $3.94 \mathrm{~g} / \mathrm{kg}$ (Table 4.1 a5) during the DAP, respectively. The corresponding mean $\mathrm{T}_{\mathrm{g}}$ and $\mathrm{q}_{\mathrm{sat}}\left(\mathrm{T}_{\mathrm{g}}\right)-\mathrm{q}_{\mathrm{a}}$ from the $2 \mathrm{GSP}$ are $13.68^{\circ} \mathrm{C}$ and $4.34 \mathrm{~g} / \mathrm{kg}$, respectively (Table $4.1 \mathrm{a} 3$ ). In comparison to the $4 \mathrm{GSP}$, the $\mathrm{Ng} 4 \mathrm{GSP}$ reduces the daytime RMS error by almost $20 \mathrm{Wm}^{-2}$ (from 110 to $93 \mathrm{Wm}^{-2}$ ) immediately after the DAP (FP of 12-24 hr). The Ng4GSP also leads to a better estimation of daytime LHF during the 25-48 $\mathrm{hr}$ and 49-72 $\mathrm{hr}$ FPs. The primary reason for the Ng4GSP to have a better estimation of daytime LHF is likewise that the mean $T_{g}$ and $q_{\text {sat }}\left(T_{g}\right)-q_{a}$ in the Ng4GSP are greatly reduced during the DAP. There is a $40 \%$ reduction of $q_{\text {sat }}\left(T_{g}\right)-q_{a}$ in the Ng4GSP as compared to the 4GSP, which means less soil moisture is available after the DAP in the Ng4GSP such that the model's capability to correctly estimate daytime LHF is greatly enhanced. 


\subsubsection{For PM method}

The inclusion of GOES data can aid in enhancing the advantage of the PM method of estimating daytime LHF due to an effective decrease of $T_{a}$ and $q_{\text {sat }}\left(T_{a}\right)-q_{a}$ during the DAP in the 1GSP, 2GSP, and 4GSP, when compared to the 0GSP (Table 4.1b2, b3, b4). In addition, the incorporation of GOES data obviously enhances the advantage of the PM method over the bucket method in calculating daytime LHF. The RMS errors in estimating daytime LHF are 104 and $90 \mathrm{Wm}^{-2}$ during the FPs of 1-24 hr and 25-48 hr, respectively, from the 0GSP with the PM method (Fig. 4.4a). In contrast, the 1GSP using the PM method causes the corresponding RMS errors to be lowered to 51 and $70 \mathrm{Wm}^{-2}$ (Fig. 4.4a), respectively. When compared to the 0GSP, the assimilation of 2 sets of GOES data, at $00 \mathrm{Z}$ and $12 \mathrm{Z}$, also causes the model using the PM method (hereafter, MPM) to improve its calculation of daytime LHF (Fig. 4.4b) in the FP of 1-24 hr and 25-48 hr due to a notable reduction of $T_{a}$ and a 35\% reduction of $q_{s a t}\left(T_{a}\right)-q_{a}$ during the DAP (Table $4.1 \mathrm{~b} 3$ ). Relative to the OGSP, the assimilation of 4 sets of GOES data into the MPM leads to a significant decrease of $T_{a}$ and a $43 \%$ decrease in $q_{s a t}\left(T_{a}\right)-q_{a}$ during the DAP (Table $4.1 \mathrm{~b} 4$ ). This then dramatically reduces the RMS errors for estimating daytime LHF immediately after the DAP and during the $25-48 \mathrm{hr} \mathrm{FP}$ (from 104 to $58 \mathrm{Wm}^{-2}$ and from 90 to $52 \mathrm{Wm}^{-2}$, in the 1-24 hr and 25-48 hr FPs, respectively; Fig. 4.4c). For the 49-72 hr FP, the positive influence of GOES data insertion on the model's estimation of daytime LHF is less pronounced. The RMS error is $41 \mathrm{Wm}^{-2}$ for the 0GSP and is $34 \mathrm{Wm}^{-2}$ for the 4GSP with the PM method (Fig. 4.4c).

Nudging the model's temperature toward the GOES data at $12 \mathrm{Z}$ further decreases $\mathrm{T}_{\mathrm{a}}$ to a mean value of $15.73^{\circ} \mathrm{C}$, and further decreases $\mathrm{q}_{\text {sat }}\left(\mathrm{T}_{\mathrm{a}}\right)-\mathrm{q}_{\mathrm{a}}$ to a mean value of $5.78 \mathrm{~g} / \mathrm{kg}$ during the DAP (Table $4.1 \mathrm{~b} 5$ ), such that the MPM is able to make a more reliable prediction of daytime LHF during the simulation period. The 2GSP results in RMS errors of 75, 83, and 41 $\mathrm{Wm}^{-2}$ in the 1-24 hr, 25-48 hr, and 49-72 hr FPs (Fig. 4.4b), respectively. The corresponding RMS errors from the Ng2GSP are 62,45 , and $29 \mathrm{Wm}^{-2}$. Nudging the MPM toward the 4 sets of GOES data further helps the model to generate a more accurate estimation of daytime LHF than the MPM without GOES data insertion, owing to a pronounced reduction of $\mathrm{T}_{\mathrm{a}}$ and a $62 \%$ decrease in $\mathrm{q}_{\text {sat }}\left(\mathrm{T}_{\mathrm{a}}\right.$ )- qa during the DAP (Table 4.1b5). The resulting RMS errors during the 1$24 \mathrm{hr}, 25-48 \mathrm{hr}$, and 49-72 hr FPs from the Ng4GSP with the PM method are 56, 42, and 27 $\mathrm{Wm}^{-2}$ (Fig. 4.4e), respectively. With the PM method, the Ng4GSP and Ng2GSP lead to comparable RMS errors in estimating LHF owing to the fact that the degree of decrease in $T_{a}$ and in $\mathrm{q}_{\mathrm{sat}}\left(\mathrm{T}_{\mathrm{a}}\right)-\mathrm{q}_{\mathrm{a}}$ during the DAP from both experiments are similar to each other (Table $4.1 \mathrm{~b} 5$ and $b 6$ ). It is also noted that the Ng4GSP with the bucket method leads to a better estimation of daytime LHF than the 0GSP with the PM method during the ensuing simulation period (Fig. 4. $4 \mathrm{e}$ ), because the potential ET is dramatically decreased as a result of significant reduction in surface moisture gradient.

The results from the 0GSP, 1GSP, and Ng2GSP are taken as examples for the following discussion. Hourly averaged SHF, LHF, $\mathrm{R}_{\text {net }}, \mathrm{T}_{\mathrm{g}}, \mathrm{T}_{\mathrm{a}}$ or $\mathrm{q}_{\mathrm{a}}$ in 3 different FPs are selectively presented in Figs. 4.5, 4.6, and 4.7. In these figures, solid lines are observations from the SGP ARM site, dashed lines are quantities from the MBK, and dotted lines are quantities from the MPM. It should be confirmed that the adjustment process of the model during the DAP (the 
first $12 \mathrm{hr}$ period of model integration) results in zigzags of the lines shown in the figures for the 1-24 hr FP. The variation of the quantities during the DAP will then not be of concern.

\subsubsection{For 1-24 hr forecast period (including $12 \mathrm{hr}$ of the DAP and the first $12 \mathrm{hr}$ of the simulation period)}

Without the GOES data insertion, the MBK and MPM overestimate the daytime LHF by $116 \%$ and $88 \%$, respectively (Fig. 4.5.1a). There is less evaporative cooling associated with the PM method, such that the skin temperature $\left(\mathrm{T}_{\mathrm{g}}\right.$ ) of the MPM is then $0.6^{\circ} \mathrm{C}$ or $9 \%$ warmer than that for the MBK (Fig. 4.5.1d). This leads to an increase in SHF (Fig. 4.5.1b) and a decrease in moisture content at the lowest model level (Fig. 4.5.1f) during the daytime in the MPM. Less chance of low-level cloud formation is then expected due to the use of the PM method, thus, more incoming solar radiation is able to reach the model's ground surface and a higher $\mathrm{R}_{\text {net }}$ from the MPM is foreseeable. In this case, there is a $12 \%$ overestimation of $\mathrm{R}_{\text {net }}$ by the MBK and a $14 \%$ overestimation by the MPM (Fig. 4.5.1c). The model without the GOES data insertion has a very poor capability of estimating the daytime Ta (Fig. 4.5.1e) because of inappropriate SHF simulation.

The assimilation of GOES data at the beginning of the model integration (1GSP) cools the model's low-level atmosphere and ground surface during the DAP owing to a cooler lower half of the atmosphere from GOES data in the central $U$. S. The $T_{g}$ and $T_{a}$ are lowered (Fig. 4. 6.1c and d) owing to the GOES data insertion, therefore water molecules have less kinetic energy to escape from the ground surface into the atmosphere. Thereafter, the degrees of overestimating daytime LHF by both the bucket and PM methods are decreased, with respective degrees of overestimation of $82 \%$ and $30 \%$ (Fig. 4.6.1a). The estimated $R_{n e t}$ from the 1 GSP is lowered and is more realistic (4\% overestimation for the bucket method and 5\% for the PM method) compared to that from the 0GSP (Fig. 4.6.1b), resulting from a weaker downward longwave radiation owing to a cooling of the model's low-level atmosphere when the GOES data are assimilated. Daytime $\mathrm{q}_{\mathrm{a}}$ is then more accurately estimated (Fig. 4.6.1e) due to the insertion of GOES data, as a result of less LHF from the model's ground surface.

Nudging the model's temperature toward the temperature field with the GOES temperature data at $12 \mathrm{Z}(\mathrm{Ng} 2 \mathrm{GSP})$ causes the model's $\mathrm{T}_{\mathrm{g}}$ and $\mathrm{T}_{\mathrm{a}}$ to be even cooler than those from the 0GSP (Fig. 4.7.1c and d). This then leads to a more realistic estimation of daytime LHF by the MBK and MPM (Fig. 4.7.1a). The $\mathrm{R}_{\text {net }}$ from the $\mathrm{Ng} 2 \mathrm{GSP}$ has some time lag relative to observation (Fig. 4.7.1b). This is due to some inaccurate prediction of the position and duration of low-level clouds over the SGP ARM site by the model. Because there is less LHF due to the GOES data insertion, $\mathrm{q}_{\mathrm{a}}$ is more reasonably predicted. For the bucket method, the Ng2GSP causes mean daytime $\mathrm{q}_{\mathrm{a}}$ to decrease by $2.0 \mathrm{~g} / \mathrm{kg}$ or $30 \%$ less compared to the 0GSP. Using the PM method, the Ng2GSP generates a mean daytime $\mathrm{q}_{\mathrm{a}}$ that is consistent with the corresponding observation (Fig. 4.7.1e).

\subsubsection{For $25-48 \mathrm{hr}$ forecast period}

The overestimation of daytime LHF by the MBK without GOES data insertion (Fig. 4.5. 2a) results in a moistening of the low-level atmosphere. Average $q_{a}$ is estimated to be $11 \mathrm{~g} / \mathrm{kg}$, 

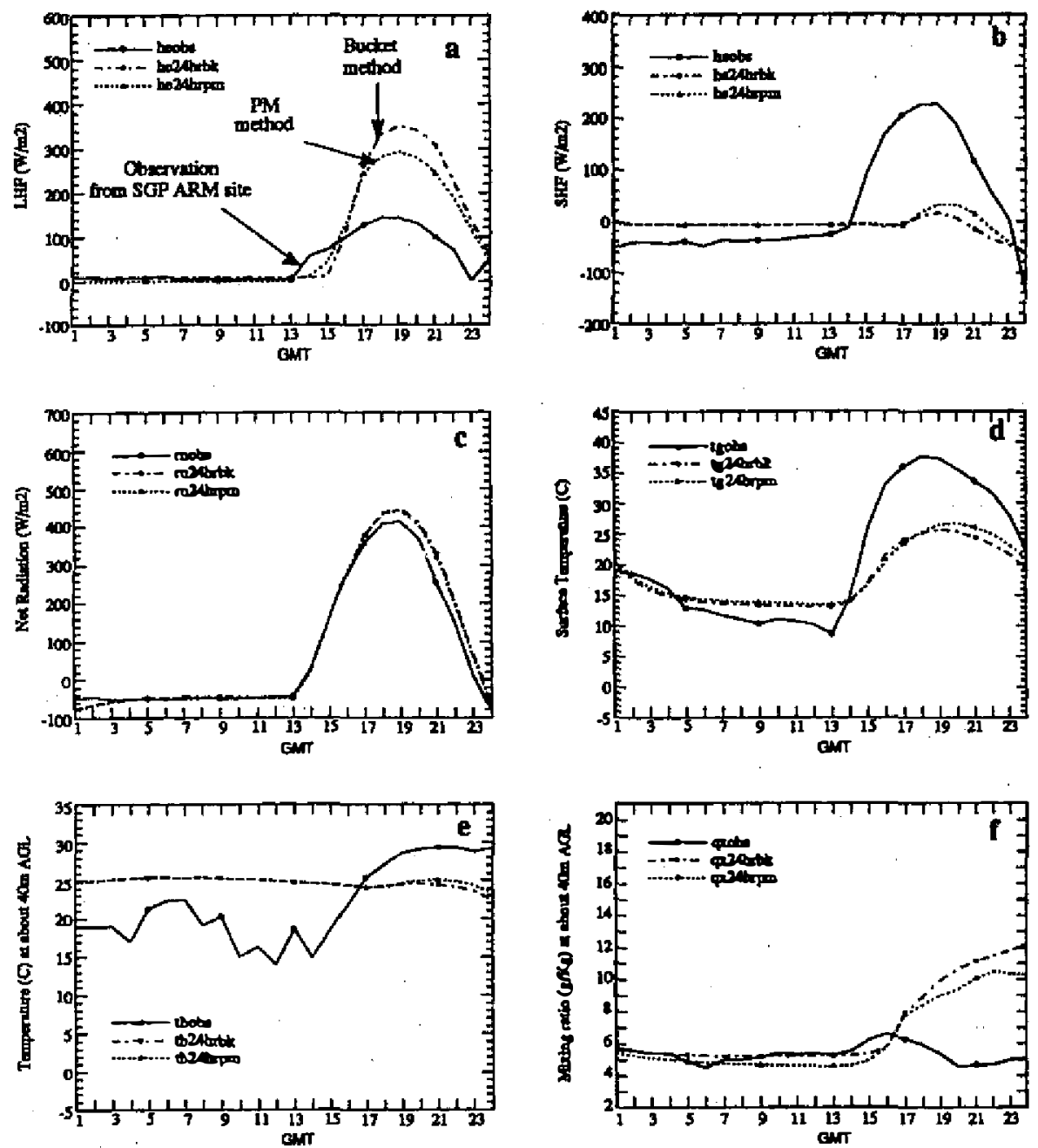

Fig. 4.5.1. Hourly average of (a) latent heat flux $\left(\mathrm{Wm}^{-2}\right)$, (b) sensible heat flux $\left(\mathrm{Wm}^{-2}\right),(\mathrm{c})$ net radiation at the ground surface $\left(\mathrm{Wm}^{-2}\right)$, (d) ground surface temperature $\left({ }^{\circ} \mathrm{C}\right),(\mathrm{e})$ temperature $\left({ }^{\circ} \mathrm{C}\right)$ at the lowest model level (about $40 \mathrm{~m}$ above ground level), (f) mixing ratio $(\mathrm{g} / \mathrm{kg}$ ) at the lowest model level, in model's 1-24 hr forecast period on October 16, 1995 from 0GSP. Solid line stands for the corresponding observation from the SGP ARM site, dashed line for the MBK, dotted line for the MPM. The adjustment process of the model during the DAP (the first $12 \mathrm{hr}$ period of model integration) results in zigzags for the lines shown in the figures. The variation of the quantities during the DAP will thus not be of concern.

which is $100 \%$ greater than the corresponding observation (Fig. 4.5.2c). This would be followed by a greater chance of low-level cloud formation, wherein shortwave radiation has less probability of reaching the model's ground surface, hence, the MBK has an 14\% underestima- 
tion of daytime $\mathrm{R}_{\text {net }}$ as shown in Fig. 4.5.2b. The assimilation of GOES data cools the model's low-level atmosphere, therefore, the MBK shows an obvious improvement in the estimation of daytime LHF. The degree of overestimating $\mathrm{q}_{\mathrm{a}}$ in $1 \mathrm{GSP}$ is then decreased (Fig. 4.6.2c). Since the PM method leads to less LHF (Fig. 4.6.2a), the moisture variation at the lowest model level is then more realistic and is less humid than that from the 0GSP (Fig. 4.6.2c). Subsequently, more shortwave radiation is able to extent to the model's ground surface and the $\mathrm{R}_{\text {net }}$ estimation by the MPM is more accurate than that by the MBK (Fig. 4.6.2b and 4.7.2). Using the bucket method, the average daytime $\mathrm{R}_{\text {net }}$ values are 162,172 , and $147 \mathrm{Wm}^{-2}$ from the 0GSP, 1GSP, and Ng2GSP, respectively; and using the PM method, average daytime $\mathrm{R}_{\text {net }}$ values are 208, 207, and $173 \mathrm{Wm}^{-2}$ from the 0GSP, 1GSP, and Ng2GSP, respectively. Observations show a mean value of $189 \mathrm{Wm}^{-2}$.

\subsubsection{For 49-72 hr forecast period}

In this FP, the 0GSP with the bucket method results in a stratiform rainfall rate of 55 $\mathrm{Wm}^{-2}$ (or $1.0 \mathrm{~mm}$ in this $24 \mathrm{hr}$ period) at the SGP ARM site, yet there is no rainfall observed at the SGP ARM site during this time period. The rainfall event at the SGP ARM site produced by the MBK without GOES data insertion leads to an overestimation of $q_{a}$ and underestimation of $R_{\text {net }}$ (Fig. 4.5.3b and c), owing to the existence of rain clouds and low-level cloudiness. The evaporation of rain drops further moistens the model's low-level atmosphere. A further increased possibility of low-level cloud formation is thus expected. There would be more chance for the incoming shortwave radiation to be blocked by these low-level clouds. Consequently, the MBK results in an 70\% underestimation of $\mathrm{R}_{\text {net }}$ in this FP due to an incorrect prediction of stratiform rainfall by the MBK without GOES data insertion. As qa is predicted to be too high, $\mathrm{q}_{\mathrm{sat}}\left(\mathrm{T}_{\mathrm{g}}\right)-\mathrm{q}_{\mathrm{a}}$ is small enough $(2.5 \mathrm{~g} / \mathrm{kg}$ for the bucket method) to lead to underestimation of LHF during this FP (Fig. 4.5.3a). However, the assimilation of GOES data leads the MBK to have no spurious rainfall at the SGP ARM site. Thereafter, the LHF estimated by the 1GSP with bucket method is more realistic (Fig. 4.6.3). It is found that the PM method in the 0GSP, 1GSP, and Ng2GSP does not lead to precipitation during this period of time. The overestimation of LHF by the PM method is mainly due to the inappropriate assignment of stomatal resistance. The stomatal resistance is set too low $\left(90 \mathrm{sm}^{-1}\right)$ for this case in this time period (see CL97 for the discussion on stomatal resistance).

It is thus concluded, from this case study, that the assimilation of GOES data sets via GalChen's FDDA algorithm has a positive impact on the model estimation of daytime LHF. The assimilation of the GOES data causes the MBK to lower the overestimation of the LHF and to have a higher possibility of making a better estimation of LHF than the MPM without GOES data insertion, which results from an effective decrease of $T_{g}$ and the associated $q_{s a t}\left(T_{g}\right)-q_{a}$ during the DAP. The bogus stratiform rainfall generated by the MBK is then eliminated due to the assimilation of GOES data which are relatively more stable than the model atmosphere as revealed in Fig. 4.3. The incorporation of GOES data together with the use of the PM method further improves the model's capability of correctly estimating daytime LHF, owing to a significant decrease of $T_{a}$ and the associated $q_{\text {sat }}\left(T_{a}\right)-q_{a}$ during the DAP. It is also demonstrated that the proposed nudging technique can further enhance the advantages of Gal-Chen's FDDA 


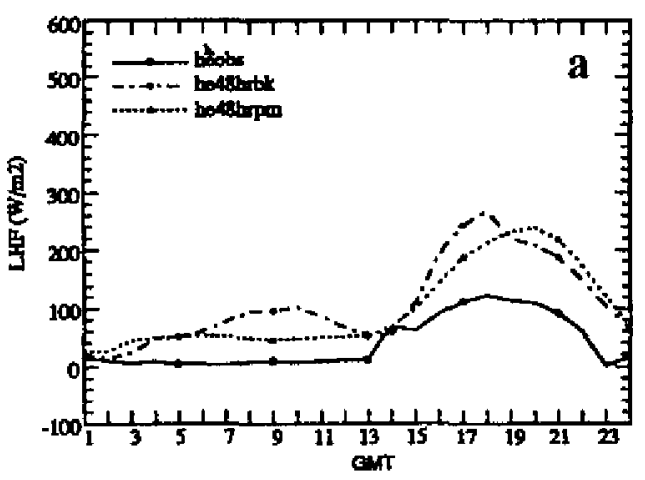

Fig. 4.5.2. Same as Fig. 4.5.1 but for 25-48 hr forecast period on October 17, 1995. (a) latent heat flux, (b) net radiation at the ground surface, and (c) mixing ratio at the lowest model level.
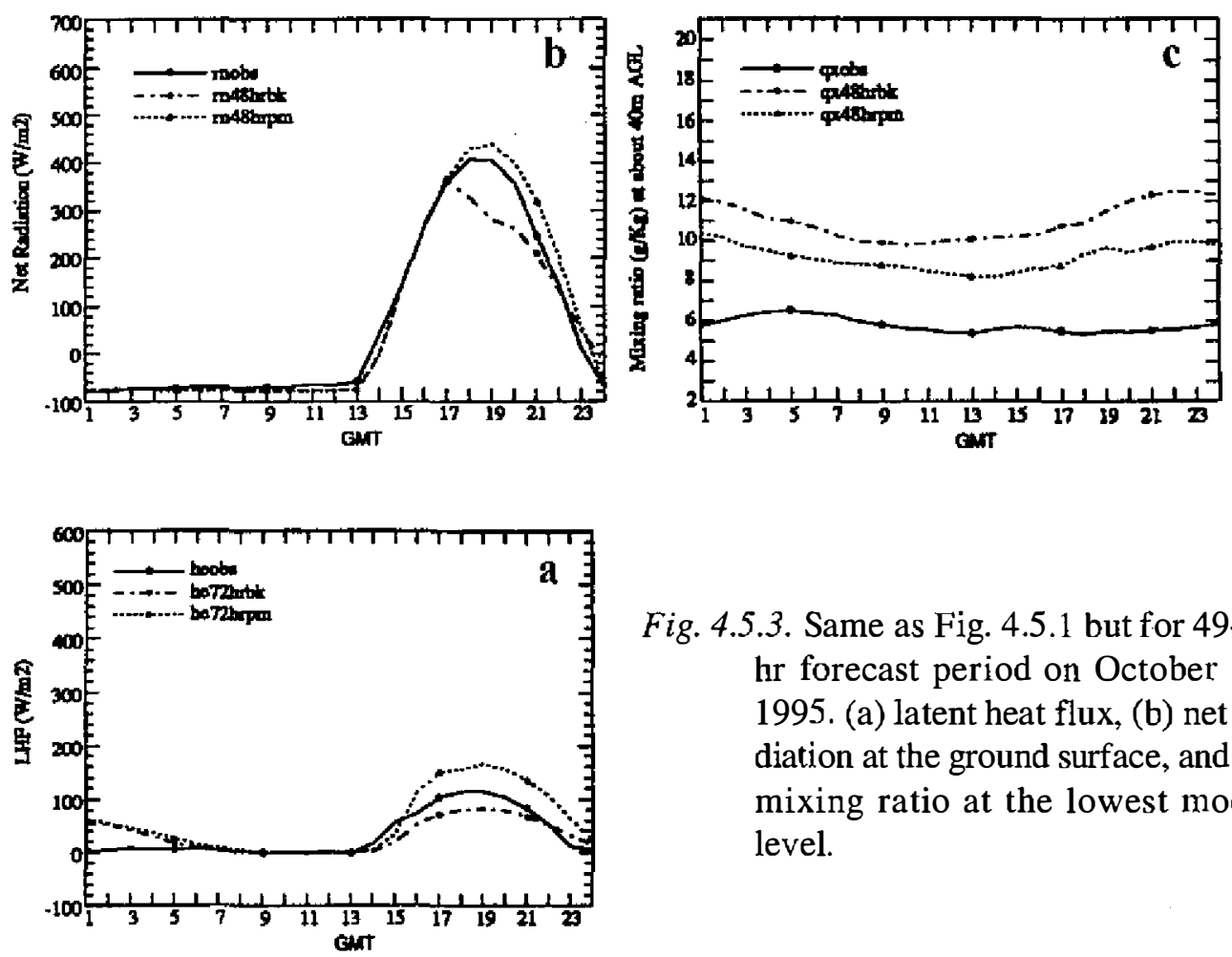

Fig. 4.5.3. Same as Fig. 4.5.1 but for 49-72 hr forecast period on October 18, 1995. (a) latent heat flux, (b) net radiation at the ground surface, and (c) mixing ratio at the lowest model level.
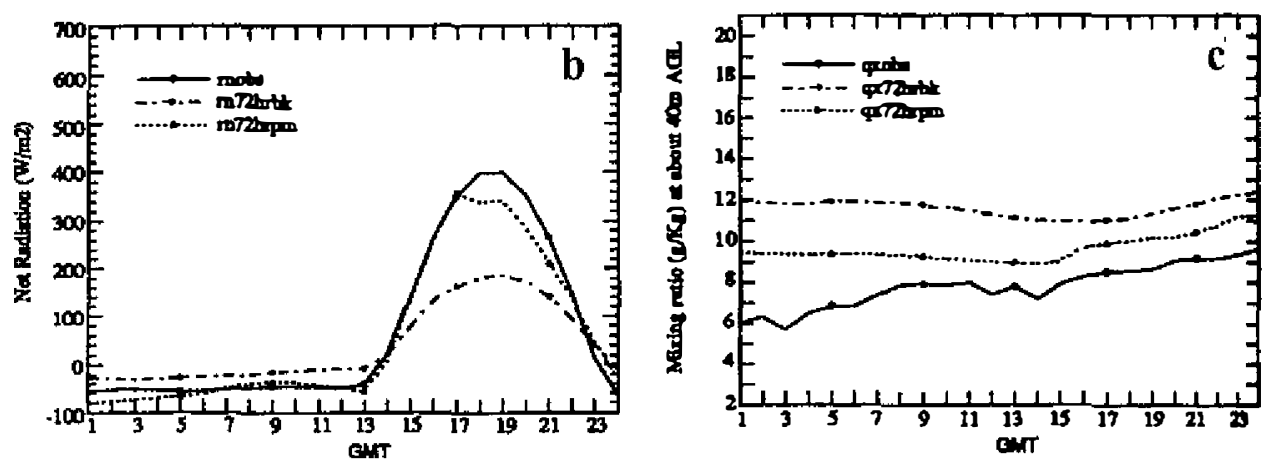

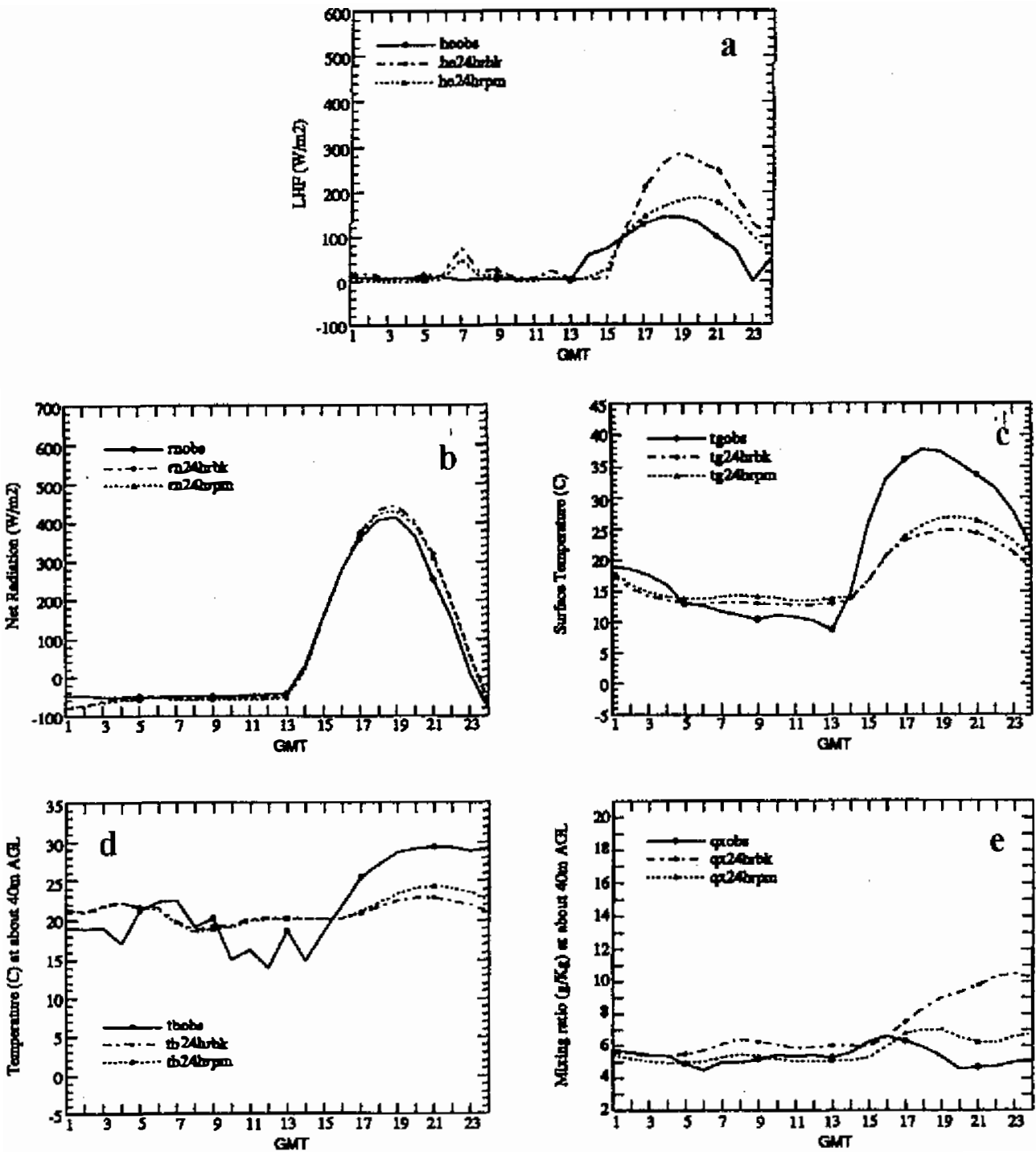

Fig. 4.6.1. Hourly average of (a) latent heat flux $\left(\mathrm{Wm}^{-2}\right)$, (b) net radiation at the ground surface $\left(\mathrm{Wm}^{-2}\right)$, (c) ground surface temperature $\left({ }^{\circ} \mathrm{C}\right),(\mathrm{d})$ temperature $\left({ }^{\circ} \mathrm{C}\right)$ at the lowest model level, (e) mixing ratio $(\mathrm{g} / \mathrm{kg})$ at the lowest model level in model's 1-24 hr forecast period on October 16, 1995 from 1GSP. Solid line stands for the corresponding observation from the SGP ARM site, dashed line for the MBK, and dotted line for the MPM.

algorithm by forcing the model to make a more reasonable estimation of daytime LHF. It is also shown that an improvement in estimating LHF will be accompanied by a more accurate estimation of low-level moisture content and net radiation at the ground surface, etc. 


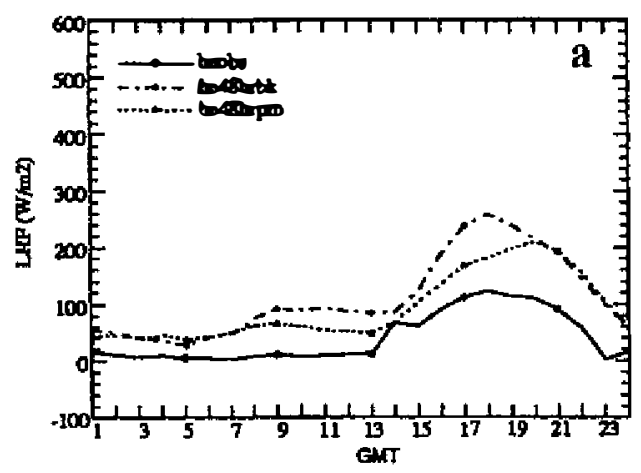

Fig. 4.6.2. Same as Fig. 4.6.1 but for 25$48 \mathrm{hr}$ forecast period on October 17, 1995. (a) latent heat flux, (b) net radiation at the ground surface, and (c) mixing ratio at the lowest model level.
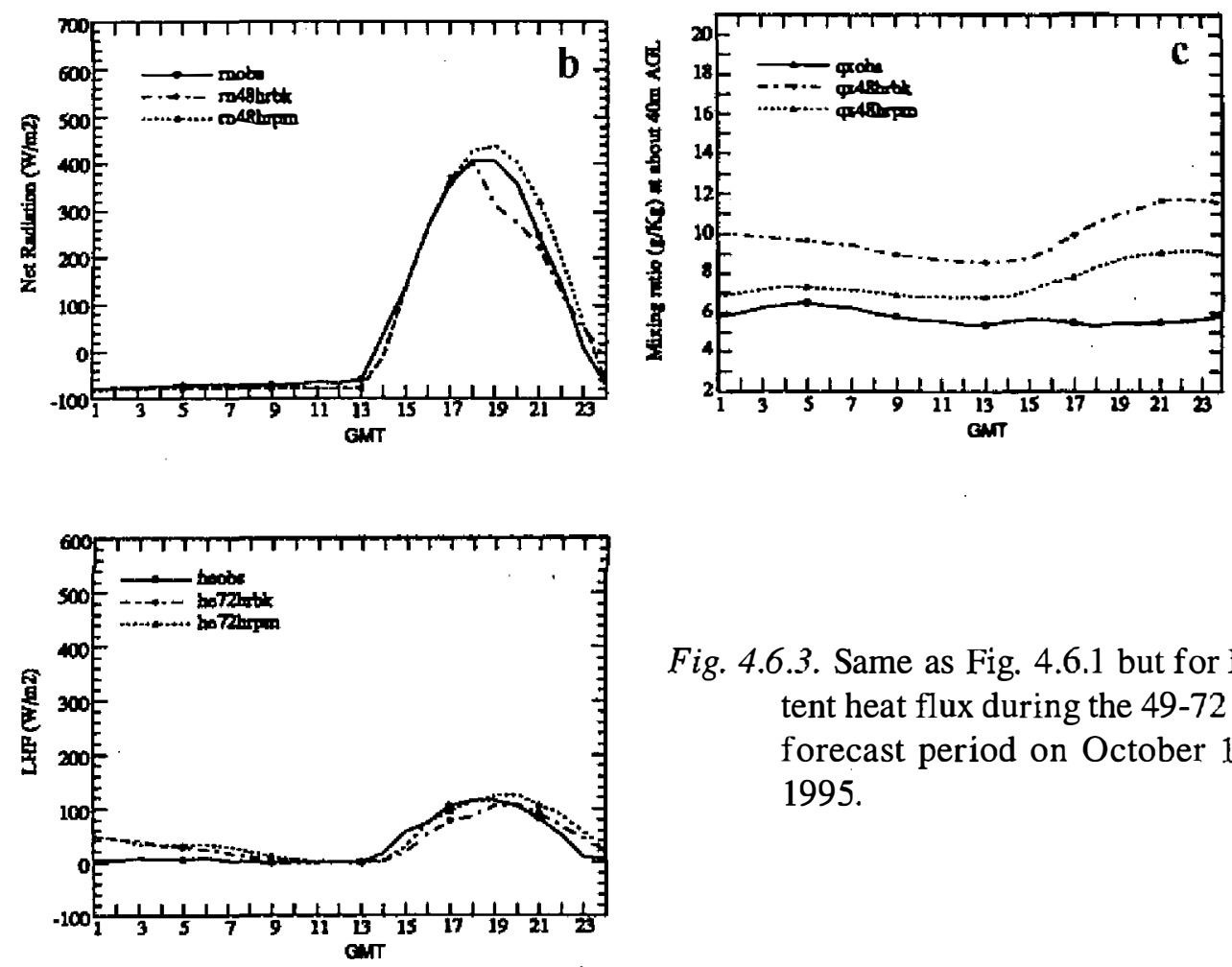

Fig. 4.6.3. Same as Fig. 4.6.1 but for latent heat flux during the $49-72 \mathrm{hr}$ forecast period on October 18, 1995.

\subsection{Assimilation of the GOES temperature data from April 2, 1995}

The GOES data on April 2 are available at 00Z, so only IGSP (static initialization) is possible on this date. The GOES sounding locations are shown in Fig. 4.8a. The domains of the mean vertical temperature differences between the GOES data and model-generated data for the bottom and top halves of the atmosphere are illustrated in Fig. $4.8 \mathrm{~b}$ and c, respectively. It is also noted from these figures, that the bottom half of the mean vertical GOES temperature field over the central U. S. is cooler than the corresponding model-generated mean vertical temperature field. 

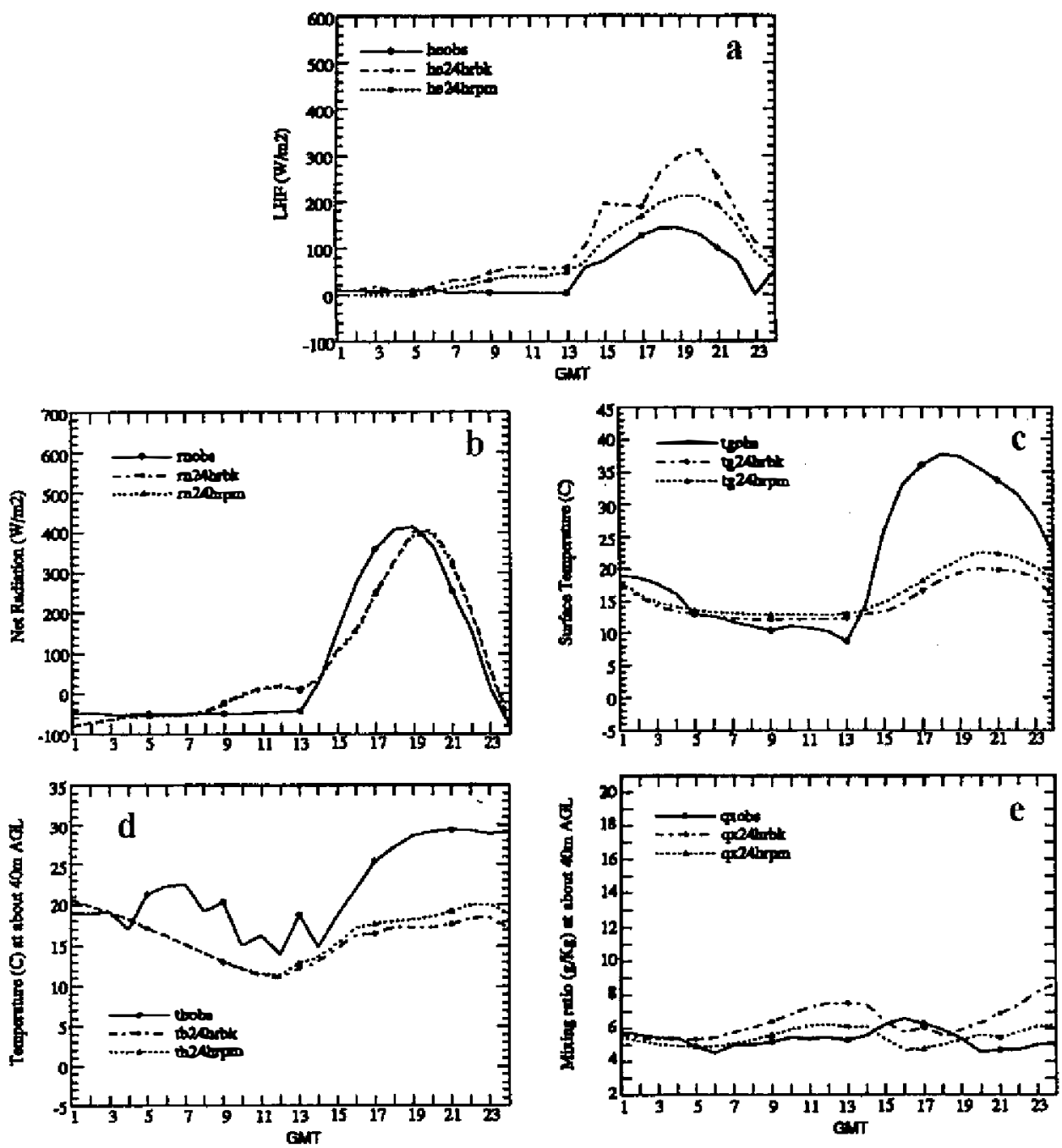

Fig. 4.7.1. Hourly average of (a) latent heat flux $\left(\mathrm{Wm}^{-2}\right)$, (b) net radiation at the ground surface $\left(\mathrm{Wm}^{-2}\right)$, (c) ground surface temperature $\left({ }^{\circ} \mathrm{C}\right),(\mathrm{d})$ temperature $\left({ }^{\circ} \mathrm{C}\right)$ at the lowest model level, and $(\mathrm{e})$ mixing ratio $(\mathrm{g} / \mathrm{kg})$ at the lowest model level in model's 1-24 hr forecast period on October 16, 1995 from Ng2GSP. Solid line stands for the corresponding observation from the SGP ARM site, dashed line for the MBK, and dotted line for the MPM.

The daytime RMS errors of the model's estimation of LHF from the 0GSP and 1GSP are illustrated in Fig. 4.9. Mean values of $\mathrm{T}_{\mathrm{g}}, \mathrm{T}_{\mathrm{a}}, \mathrm{q}_{\mathrm{sat}}\left(\mathrm{T}_{\mathrm{g}}\right)-\mathrm{q}_{\mathrm{a}}, \mathrm{q}_{\mathrm{sat}}\left(\mathrm{T}_{\mathrm{a}}\right)-\mathrm{q}_{\mathrm{a}}$, the percentage change of $\mathrm{q}_{\text {sat }}$ $\left(\mathrm{T}_{\mathrm{g}}\right)-\mathrm{q}_{\mathrm{a}}$, and $\mathrm{q}_{\text {sat }}\left(\mathrm{T}_{\mathrm{a}}\right)-\mathrm{q}_{\mathrm{a}}$ due to GOES data insertion during the DAP are listed in Table 4.2. As shown in Fig. 4.9, one can identify that the assimilation of GOES data causes the MBK to generate a more realistic estimation of daytime LHF than the MPM without the GOES data 
insertion, during the 25-48 $\mathrm{hr}$ and 49-72 $\mathrm{hr}$ FPs.

The GOES data insertion results in a 35\% reduction in $\mathrm{q}_{\text {sat }}\left(\mathrm{T}_{\mathrm{g}}\right)-\mathrm{q}_{\mathrm{a}}$ and a $47 \%$ decrease in $\mathrm{q}_{\mathrm{sat}}\left(\mathrm{T}_{\mathrm{a}}\right)-\mathrm{q}_{\mathrm{a}}$ during the DAP. Moisture content on the model's ground surface is then significantly reduced, such that the model has a higher possibility of making a better estimation of LHF during the simulation period that follows.

\subsubsection{For 1-24 hr forecast period}

The 0GSP with the PM method shows a 58\% overestimation of LHF. The assimilation of GOES data at the initial time period (1GSP) cools the model's low-level atmosphere and ground surface. The degree of overestimating daytime LHF by the MPM is then decreased to $14 \%$. Less evaporative cooling of the ground surface is then expected, such that the GOES data insertion causes the ground temperature to be warmer. Subsequently, the temperature gradient between the model's lowest level and ground surface is made to be closer to reality. The mean $\mathrm{T}_{\mathrm{g}}-\mathrm{T}_{\mathrm{a}}$ is 0.9 and $2.4^{\circ} \mathrm{C}$ in the 0GSP and 1GSP, respectively, during the 1-24 $\mathrm{hr}$ FP. The observed mean $\mathrm{T}_{\mathrm{g}}-\mathrm{T}_{\mathrm{a}}$ is $13.8^{\circ} \mathrm{C}$. The estimation of daytime SHF by the MBK and MPM with GOES data insertion is then more reasonable (comparing Fig. 4.10.1 and 4.11.1b).

\subsubsection{For 25-48 hr forecast period}

In the $0 \mathrm{GSP}$ a precipitation rate of about $300 \mathrm{Wm}^{-2}(5.2 \mathrm{~mm}$ in this $24 \mathrm{hr}$ period) is predicted by the MBK and MPM at the SGP ARM site. Yet, there was no observed rainfall during this period of time. The rainfall event at the SGP ARM site predicted by the MBK without GOES data insertion leads to an overestimation of $q_{a}$ and underestimation of daytime $R_{\text {nel }}$ by $39 \%$ (Fig. 4.10.2b), owing to the existence of rain clouds and excessive low-level cloudiness. There is less false rainfall predicted due to the more stable GOES data insertion. The MBK

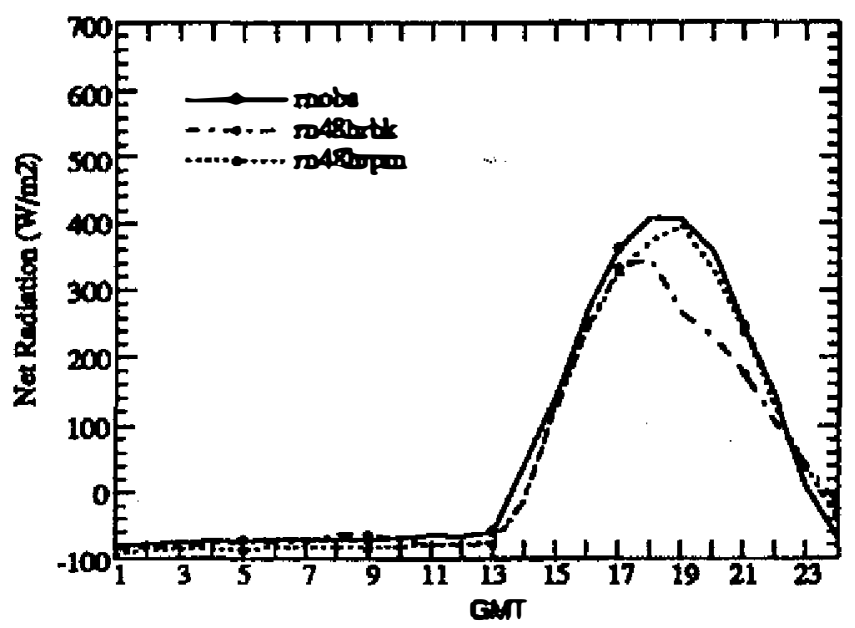

Fig. 4.7.2. Same as Fig. 4.7.1 but for net radiation at the ground surface during the 25-72 hr forecast period on October 17, 1995. 

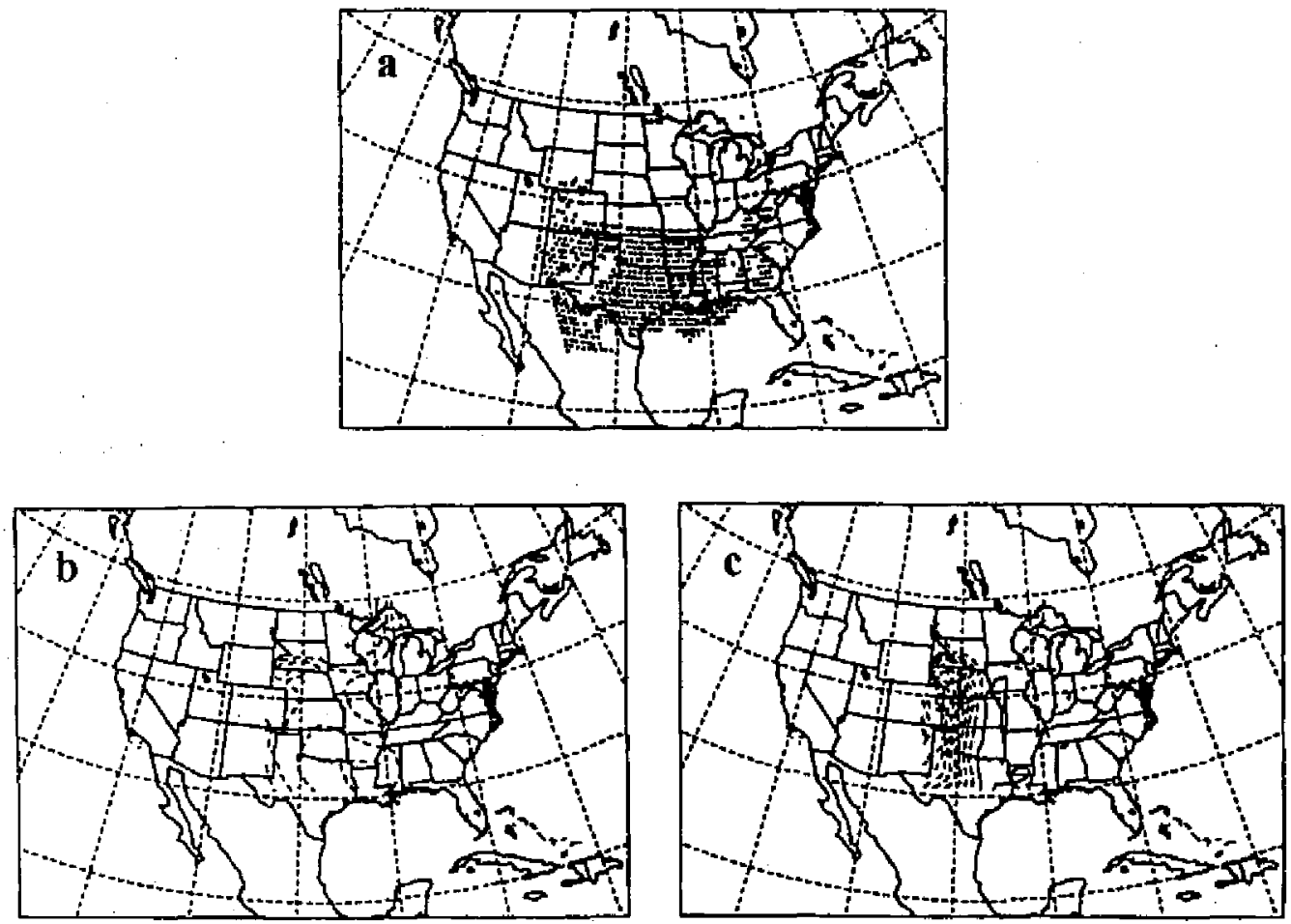

Fig. 4.8. (a) Distribution of GOES sounding locations valid at 00Z April 2, 1995; Vertically averaged temperature differences between GOES and modelgenerated data of (a) bottom half (surface to $500 \mathrm{mb}$ ) of the atmosphere; and (b) top half (500 to $50 \mathrm{mb}$ ) of the atmosphere at 00Z April 2, 1995.

Table 4.2. Same as Table 4.1 except that the GOES data used for data assimilation are from April 2, 1995.

(a) For bucket method

$\begin{array}{lccccc} & \mathrm{T}_{\mathrm{g}} & \mathrm{T}_{\mathrm{a}} & \mathrm{q}_{\mathrm{sar}}\left(\mathrm{T}_{\mathrm{g}}\right) & \mathrm{q}_{\text {sat }}\left(\mathrm{T}_{\mathrm{g}}\right)-\mathrm{q}_{\mathrm{a}} & \text { \% change } \\ \text { Observation } & 5.53 & 18.73 & 5.89 & 0.52 & \\ \text { OGSP } & 10.85 & 18.08 & 8.48 & 3.97 & \\ \text { IGSP } & 8.11 & 10.27 & 7.05 & 2.57 & -35.2\end{array}$

(b) For PM method

$\begin{array}{lccccc} & \mathrm{T}_{\mathrm{g}} & \mathrm{T}_{\mathrm{a}} & \mathrm{q}_{\mathrm{sat}}\left(\mathrm{T}_{\mathrm{a}}\right) & \mathrm{q}_{\mathrm{sar}}\left(\mathrm{T}_{\mathrm{a}}\right)-\mathrm{q}_{\mathrm{a}} & \text { \% change } \\ \text { Observation } & 5.53 & 18.73 & 13.49 & 8.12 & \\ \text { OGSP } & 11.47 & 18.02 & 12.91 & 8.89 & \\ \text { 1GSP } & 9.63 & 11.51 & 8.48 & 4.70 & -47.1\end{array}$




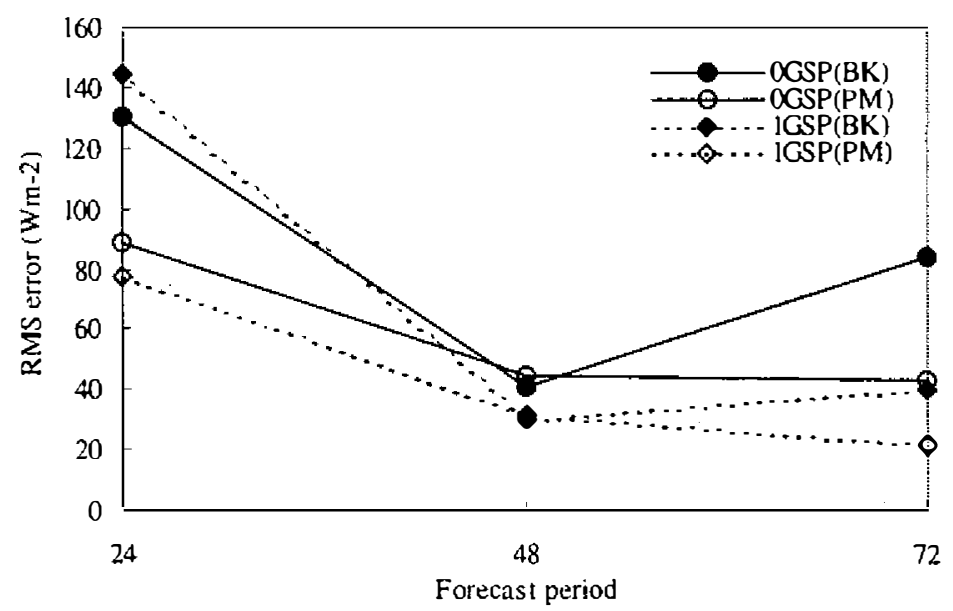

Fig. 4.9. Similar to Fig. 4.4 but using the GOES data from April 2, 1995. Dotted line with solid diamond is for 1GSP with bucket method, and dotted line with open diamond is for 1GSP with the PM method.

and MPM with GOES data insertion show rainfall rates of 200 and $90 \mathrm{Wm}^{-2}$, respectively. There are fewer raindrops evaporating in the model's low-level atmosphere in the 1GSP, such that the low-level mixing ratio is smaller. Consequently, the moisture gradient between the ground surface and lowest model level is greater and this leads to an increase in daytime LHF in the 1GSP (comparing Fig. 4.10.2a and 4.11.2). The 0GSP with the bucket and PM methods show $29 \%$ and $26 \%$ underestimation of daytime LHF, respectively. The corresponding 1GSP with the bucket and PM methods show only $1 \%$ and $2 \%$ underestimation of daytime LHF, respectively (Fig. 4.11.2).

\subsubsection{For 49-72 hr forecast period}

Observations showed no rainfall event and there is no precipitation in the MBK and MPM during this period of time. The MBK and MPM overestimate daytime LHF by $69 \%$ and $33 \%$ (Fig. 4.10.3), respectively, for the 0GSP. The corresponding 1GSP shows a more accurate estimation of daytime LHF (Fig. 4.11.3).

It is thus also concluded from this case study that the assimilation of GOES data using the proposed FDDA algorithm tends to have positive impacts on the model's estimation of daytime LHF, which results from an effective decrease in $\mathrm{T}_{\mathrm{g}}, \mathrm{T}_{\mathrm{a}}$, and the associated $\mathrm{q}_{\mathrm{sat}}\left(\mathrm{T}_{\mathrm{g}}\right)-\mathrm{q}_{\mathrm{a}}$ and $\mathrm{q}_{\mathrm{sat}}\left(\mathrm{T}_{\mathrm{a}}\right)-\mathrm{q}_{\mathrm{a}}$ during the DAP. Most of the bogus stratiform rainfall generated by the model is eliminated, as a result of relatively more stable GOES data insertion.

Similar experiments are conducted using the GOES temperature data from January 9, 1995 , which are available only at 12Z. It shows that the assimilation of GOES data via GalChen's FDDA algorithm and nudging the model's temperature toward the GOES data at $12 \mathrm{Z}$ have a less positive impact on the model's estimation of daytime LHF than the previous two cases, which results from an insufficient decrease in $\mathrm{T}_{\mathrm{g}}, \mathrm{T}_{\mathrm{a}}$, and the associated $\mathrm{q}_{\mathrm{sat}}\left(\mathrm{T}_{\mathrm{g}}\right)-\mathrm{q}_{\mathrm{a}}$, and 


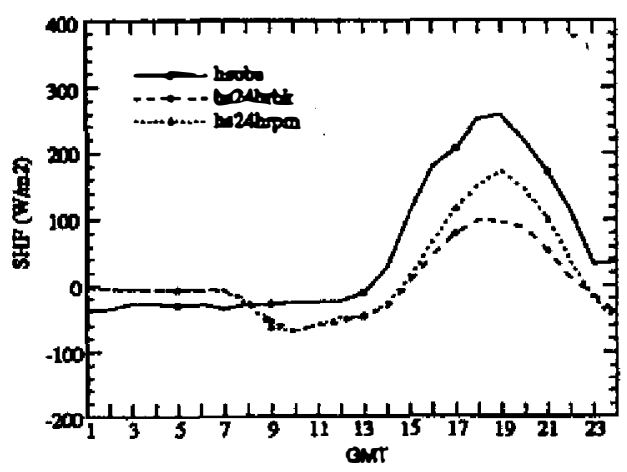

Fig. 4.10.1. Hourly average of sensible heat flux $\left(\mathrm{Wm}^{-2}\right)$ in model's $1-24 \mathrm{hr}$ forecast period on April 2, 1995 from 0GSP. Solid line stands for the corresponding observation from the SGP ARM site, dashed line for the MBK, and dotted line for the MPM.
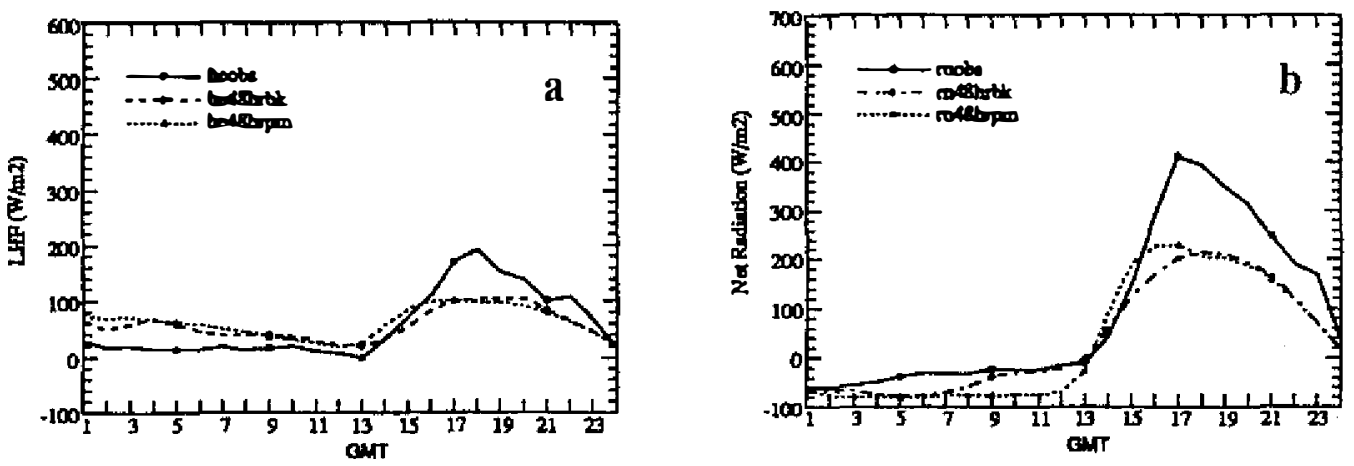

Fig. 4.10.2. Same as Fig. 4.10.1 but for (a) latent heat flux, and (b) net radiation at the ground surface during 25-48 hr forecast period on April 3, 1995.

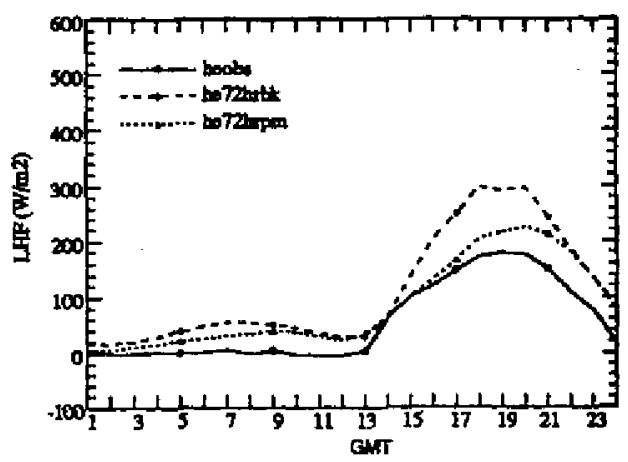

Fig. 4.10.3. Same as 4.10 .1 but for latent heat flux during $49-72 \mathrm{hr}$ forecast period on April 4, 1995.

$\mathrm{q}_{\text {sat }}\left(\mathrm{T}_{\mathrm{a}}\right)-\mathrm{q}_{\mathrm{a}}$ during the DAP. There is only a 10\% reduction in $\mathrm{q}_{\text {sat }}\left(\mathrm{T}_{\mathrm{g}}\right)-\mathrm{q}_{\mathrm{a}}$ and $\mathrm{q}_{\text {sat }}\left(\mathrm{T}_{\mathrm{a}}\right)-\mathrm{q}_{\mathrm{a}}$ during the DAP, such that the MBK and MPM with GOES data insertion show less than $15 \%$ improvement in the estimated LHF in the ensuing simulation period. In the 49-72 $\mathrm{hr}$ FP, the 0GSP with the bucket method has a stratiform rainfall rate of $17 \mathrm{Wm}^{-2}(0.32 \mathrm{~mm}$ in the $24 \mathrm{hr}$ period) over the SGP ARM site. However, no rain was observed during the same period. The 

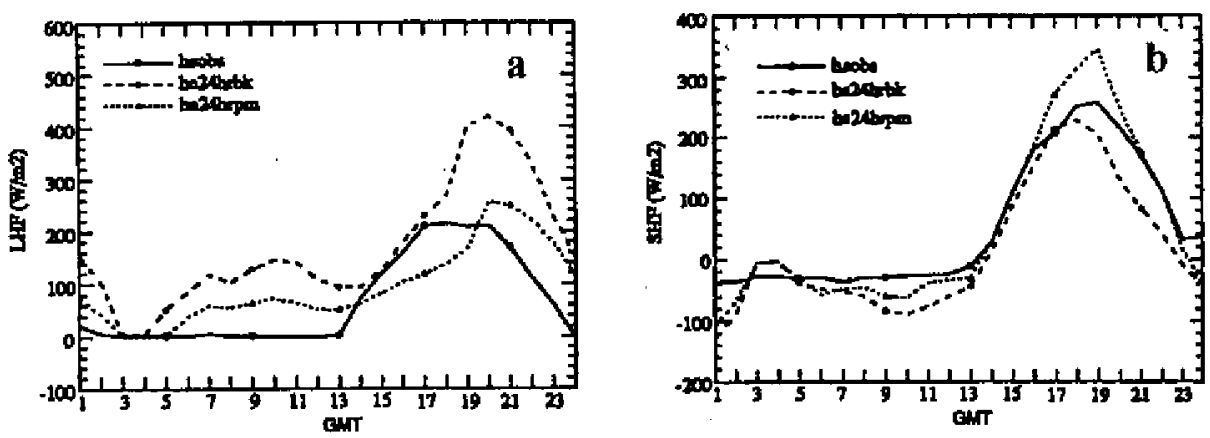

Fig. 4.11.1. Hourly average of (a) latent heat flux $\left(\mathrm{Wm}^{-2}\right)$, and (b) sensible heat flux (Wm ${ }^{-2}$ ), in model's 1-24 hr forecast period on April 2, 1995 from 1GSP. Solid line stands for the corresponding observation from the SGP ARM site, dashed line for the MBK, and dotted line for the MPM.

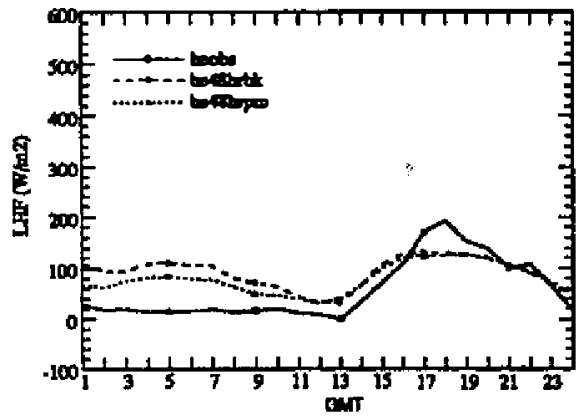

Fig. 4.11.2. Same as 4.11.1 but for latent heat flux during $25-48 \mathrm{hr}$ forecast period on April 3, 1995.

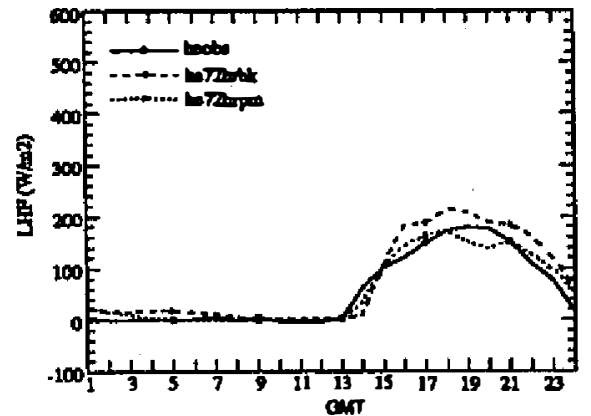

Fig. 4.11.3. Same as 4.11.1 but for latent heat flux during $49-72 \mathrm{hr}$ forecast period on April 4, 1995.

assimilation of relatively stable GOES data leads to the disappearance of bogus stratiform rainfall and causes excessive cloudiness over the SGP ARM site instead. The excessive cloudiness is neither completely removed nor reduced by the assimilation of GOES data, and thus, there is little improvement in estimating $R_{\text {ncl }}, q_{a}$, by either the MBK or MPM with GOES data insertion. The GOES data obtained from the NESDIS in July 1995 have an extensive data void area, mainly due to excessive cloudiness, over the Colorado, New Mexico, Kansas, Oklahoma and Texas area. There is little information from the GOES data that is of use for data assimilation. Therefore, there is no case study for July 1995.

\section{SUMMARY AND CONCLUSIONS}

Surface moisture flux over land is an important forcing mechanism for the atmosphere 
over continents on a wide range of spatial and temporal scales. It affects the formation process of low-level clouds or even precipitation. Segal et al. (1995) scaled the dependency of local convection on the Bowen ratio over uniform surfaces. They showed that a smaller Bowen ratio (the latent heat flux is greater than the sensible heat flux) would result in a higher thermodynamic potential for deep convection. Much better precipitation forecasts can be expected due to a more realistic thermodynamic profile resulting from an improved estimation of ET (Beljaars et al. 1996). Pan et al. (1996) demonstrated that a transient increase in soil moisture enhanced the total rainfall over their simulation domain. The increase in soil moisture could increase local rainfall when the lower atmosphere was thermally unstable and relatively dry. Thus, a more accurate estimation of surface ET will be very beneficial to the understanding of atmosphere-land exchange process and to the comprehension of formation mechanisms of lowlevel clouds and precipitation. In Part I of this study, the superiority of the PM method over the bucket method to parameterize surface ET was demonstrated. In Part II, a variational FDDA technique proposed by Gal-Chen $(1983,1986)$ is implemented into the PSU/NCAR MM4 system to study the impact of satellite measurements on the model's estimation of surface ET. As shown in CL97, a better estimation of daytime LHF will allow the model to make improved estimations of sensible heat flux, net radiation at the ground surface, low-level moisture content, etc. Results from the OSSEs and real GOES data assimilation experiments indicate that the assimilation of satellite temperature measurements can cause not only a decrease in surface temperature $T_{g}$, and the associated moisture gradient at the ground surface $q_{\text {sat }}\left(T_{g}\right)$ $\mathrm{q}_{\mathrm{a}}$, but also a reduction in temperature at the lowest model level $\mathrm{T}_{\mathrm{a}}$, and the associated mixing ratio depression at the lowest model level $\mathrm{q}_{\mathrm{sat}}\left(\mathrm{T}_{\mathrm{a}}\right)-\mathrm{q}_{\mathrm{a}}$. The potential ET in the model's ground surface is then decreased during the DAP, such that the model is able to make better estimations of surface ET during the ensuing simulation or forecast period.

Several important findings from the FDDA experiments are summarized as follows:

(1) The OSSEs indicate that the ground surface temperature $\left(T_{g}\right)$, and the associated moisture gradient between the ground surface and lowest model level $\left[\mathrm{q}_{\mathrm{sat}}\left(\mathrm{T}_{\mathrm{g}}\right)-\mathrm{q}_{\mathrm{a}}\right]$, are primary contributing factors that can affect the accuracy of estimating LHF by the bucket method. The assimilation of simulated satellite data results in a decrease in these three quantities during the DAP. This is equivalent to a decrease in potential ET during the DAP, such that the degree of overestimating LHF by the bucket method is decreased after the DAP:

(2) It reveals that temperature at the lowest model level $\left(T_{a}\right)$ and the associated mixing ratio depression $\left[q_{\text {sat }}\left(T_{a}\right)-q_{a}\right]$ at the lowest model level are the main factors that control the accuracy of estimating LHF by the PM method when the stomatal resistance is held constant. The incorporation of simulated satellite data leads to a decrease in $T_{\mathrm{a}}$ and the associated $\mathrm{q}_{\mathrm{sat}}$ $\left(T_{a}\right)-q_{a}$ during the DAP. This causes a reduction in the estimated potential ET by the PM method. A more reasonable estimation of LHF by the PM method is anticipated in the ensuing simulation period.

(3) The assimilation of real GOES data via Gal-Chen's FDDA algorithm has a positive impact on the model's estimation of LHF, which results from a reduction in potential ET in the model's ground surface during the DAP, owing to a decrease in the model's mean vertical temperature of the lower atmosphere. According to the GOES temperature information, the model's lower atmosphere tends to be warmer over the central U. S. The assimilation of the 
colder GOES data in the lower atmosphere then results in a reduction in $T_{g}, T_{a}$, and the associated $q_{s a t}\left(T_{g}\right)-q_{a}, q_{s a t}\left(T_{a}\right)$ - qa during the DAP, such that the model is able to make a more realistic estimation of LHF during the forecast period.

(4) A higher frequency of GOES data insertion does not necessarily lead to a more accurate estimation of LHF by the model. Too much shock or noise, i.e., imbalance between the model's temperature/wind fields and the GOES temperature field, may be introduced into the model as the data insertion rate increases during the DAP, such that prediction may get worse.

(5) Static initialization, i.e., one set of GOES data insertion at the beginning of the model's integration, is often able to give a better estimation of LHF. This means it will be very feasible for operational numerical weather prediction models to adopt this FDDA algorithm to improve their estimation of boundary layer surface fluxes, temperature, and moisture fields since there is only a need of assimilating satellite data at the starting time of the model's integration.

(6) The analysis-nudging technique used in this research can enhance the advantages of the proposed FDDA technique. The nudging technique results in a greater degree of reduction in mean $\mathrm{T}_{\mathrm{g}}, \mathrm{T}_{\mathrm{a}}$ and the associated $\mathrm{q}_{\mathrm{sat}}\left(\mathrm{T}_{\mathrm{g}}\right)-\mathrm{q}_{\mathrm{a}}$ and $\mathrm{q}_{\mathrm{sat}}\left(\mathrm{T}_{\mathrm{a}}\right)-\mathrm{q}_{\mathrm{a}}$ during the DAP. Potential ET is then further decreased during the DAP. A smaller degree of overestimation of LHF by the model using either the bucket or PM method is then anticipated during the forecast period.

(7) The bucket method tends to lead to a worse estimation of LHF than the PM method (CL97). However, the MBK with GOES data insertion has a higher possibility of making a better estimation of LHF than the MPM without GOES data insertion, as long as there is an effective decrease in the mean $T_{g}$ and the associated mean $q_{\text {sat }}\left(T_{g}\right)-q_{a}$, during the DAP.

(8) The MPM with GOES data insertion tends to make a highly accurate estimation of LHF after the DAP, due to a sufficient decrease ( $20 \%$ or above) in potential ET resulting from a pronounced decrease in mean $T_{a}$, and the associated mean $q_{s a t}\left(T_{a}\right)-q_{a}$, during the D.AP. On the other hand, when the decrease in $\mathrm{q}_{\mathrm{sat}}\left(\mathrm{T}_{\mathrm{g}}\right)-\mathrm{q}_{\mathrm{a}}, \mathrm{q}_{\mathrm{sat}}\left(\mathrm{T}_{\mathrm{a}}\right)-\mathrm{q}_{\mathrm{a}}$ is less than $10 \%$ during the DAP, the positive impact of GOES data insertion on the model's estimation of daytime LHF is minimal.

(9) There is a higher possibility of excessive low-level cloudiness or false stratiform precipitation in the MBK than that in the MPM since the bucket method has an inherent tendency to provide excessive moisture supply from the ground surface (CL97). The model using the PM method, which has an upper bound to estimate the LHF (CL97), shows no or less precipitation in the same period. The assimilation of GOES data, whose vertically averaged temperature is cooler in the lower atmosphere and warmer in the upper atmosphere over the central U. S., makes the model's atmosphere more stable. Thus, the model with GOES data insertion has a smaller probability of generating spurious stratiform rainfall over the SGP ARM site. Subsequently, the SHF, Rnet, etc., estimated by the model are more reasonable.

Acknowledgments The authors would like to thank Dr. Robert Rabin of National Severe Storm Laboratory for offering all the GOES retrievals for the real satellite data assimilation experiment. It is always wonderful to remember the first author's advisor, the late Dr. Tzvi 
Gal-Chen, for his stimulating advice and outstanding mentorship. The first author's appreciation also goes to Mr. Shinn-Liang Shieh, director-general of the Central Weather Bureau of Taiwan. Without Mr. Shieh's enthusiastic encouragement and spiritual support, the first author would never have had the excellent opportunity to study at the University of Oklahoma. This research was supported by the Atmospheric Radiation Measurement program of the US Department of Energy.

\section{REFERENCES}

Anthes, R. A., 1974: Data assimilation and initialization of hurricane prediction models. $J$. Atmos. Sci., 31, 702-719.

Anthes, R. A., 1977: A cumulus parameterization scheme utilizing a one-dimensional cloud model. Mon. Wea. Rev., 105, 270-286.

Anthes, R. A., and T. T. Wamer, 1978: Development of hydrodynamic models suitable for air pollution and other mesometeorological studies. Mon. Wea. Rev., 106, 1045-1078.

Anthes, R. A., E. Y.Hsie, and Y.-H. Kou, 1987: Description of the Penn State/NCAR mesoscale model version 4 (MM4). NCAR Tech. Note NCAR/TN-282+STR, 66pp.

Aune, R. M., L. W. Uccellini, R. A. Peterson, and J. J. Tuccillo, 1987: A VAS-numerical model impact study using the Gal-Chen variational approach. Mon. Wea. Rev., 115, 1009-1035.

Beljaars, A. C. M., P. Viterbo, M. J. Miller, and A. K. Betts, 1996: The anomalous rainfall over the United States during July 1993: Sensitivity to land surface parameterization and soil moisture anomalies. Mon. Wea. Rev., 124, 362-383.

Bell, R. S., 1986: The meteorological office fine-mesh data assimilation scheme. Meteor. Mag., 115, 161-177.

Bolin, B., 1953: The adjustment of a nonbalanced velocity field towards geostrophic equilibrium in a stratified fluid. Tellus, 5, 373-385.

Bleck, R., 1977: Numerical simulation of lee cyclogenesis in the Gulf of Genoa. Mon. Wea. Rev., 105, 428-445.

Blumen, W., 1972: Geostrophic adjustment. Rev. Geophys. Space Phys., 10, 485-528.

Cahn, A., 1945: An investigation of the free oscillations of a simple current system. J. Meteor., 2, 113-119.

Caplan, P., J. Derber, W. Gemmill, S.-Y. Hong, H.-L. Pan, and D. Parrish, 1997: Changes to the 1995 NCEP operational medium-range forecast model analysis-forecast system. Wea. Forecasting, 12, 581-594.

Charney, J., M. Halem, and R. Jastrow, 1969: Use of incomplete historical data to infer the present state of the atmosphere. J. Atmos. Sci., 26, 1160-1163.

Chen, C.-R., 1996: Improved treatment of surface evapotranspiration in a mesoscale numerical model. Ph. D. dissertation, University of Oklahoma, 236pp.

Chen, C.-R., and P. J. Lamb, 1997: Improved treatment of surface evapotranspiration in a mesoscale numerical model. Part I: via the installation of the Penman-Monteith method. Terris. Atmos. Oceanic Sci., 8, 481-508. 
Chedin, A., N. Acott, C. Wahiche, and P. Moulinier, 1985: The improved initialization inversion method: A high resolution physical method for temperature retrievals from satellites of the TIROS-N series. J. Climate Appl. Meteor., 24, 128-143.

Chesters, D., L. W. Uccellini, and A. Mostek, 1982: VISSR Atmospheric Sounder (VAS) simulation experiment for a severe storm environment. Mon. Wea. Rev., 110, 198-216.

Cram, J. M., and M. L. Kaplan, 1985: Variational assimilation of VAS data into a mesoscale model: Assimilation method and sensitivity experiments. Mon. Wea. Rev., 113, 467484.

Cressman, G., 1959: An operational objective analysis system. Mon. Wea. Rev., 87, 367-374.

Davis, H. C., and R. E. Turner, 1977: Updating prediction models by dynamical relaxation: An examination of the technique. Quart. J. Roy. Meteor. Soc., 103, 225-245.

Derber, J. C., D. F. Parrish, and S. J. Lord, 1991: The new global operational analysis system at the National Meteorological Center. Wea. Forecasting, 6, 538-547.

Derber, J. C., and W.-S. Wu, 1998: The use of TOVS cloud-clear radiances in the NCEP SSI analysis system. Mon. Wea. Rev., 166, 2287-2299.

DiMego, G. J., 1988: The National Meteorological Center regional analysis system. Mon. Wea. Rev., 116, 977-1000.

Errico, R. M., 1986: Initialization of the PSU/NCAR mesoscale model. NCAR Tech. Note, NCAR/TN-270+1A, 120pp.

Eyre, J. R., 1987: On systematic errors in satellite sounding products and their climatological mean values. Quart. J. Roy. Meteor. Soc., 113, 279-292.

Eyre, J. R., and A. C. Lorenc, 1989: Direct use of satellite sounding radiances in numerical weather prediction. Meteor. Mag., 118, 13-16.

Eyre, J. R., G. A. Kelly, A. P. Mcnally, E. Andersson, and A. Persson, 1993: Assimilation of TOVS radiance information through one-dimensional variational analysis. Quart. J. Roy. Meteor. Soc., 119, 1427-1463.

Gal-Chen, T., 1983: Initialization of mesoscale models: The possible impact of remotely sensed data. Mesoscale Meteorology - Theories, Observations and Models, Ed. by T. GalChen and D. K. Lilly, 157-171.

Gal-Chen, T., B. D. Schmidt and L. W. Uccellini, 1986: Simulation experiments for testing the assimilation of geostationary satellite temperature retrievals into a numerical prediction model. Mon. Wea. Rev., 114, 1213-1230.

Hayden, C. M., G. S. Wade, and T. J. Schmit, 1996: Derived produce imagery from GOES-8. J. Appl. Meteor., 35, 153-162.

Hoke, J. E., and R. A. Anthes, 1976: The initialization of numerical models by a dynamical initialization technique. Mon. Wea. Rev., 104, 1551-1556.

Hollingsworth, A., 1986: Objective analysis for numerical weather prediction. Short- and medium-range weather prediction proc. WMO/IUGG NWP Symposium, Tokyo, 1159.

Jedlovec, G. J., 1985: An evaluation and comparison of vertical profile data from the VISSR Atmospheric Sounder (VAS). J. Atmos. Oceanic Tech., 2, 559-581.

Kalnay, E., M. Kanamitsu, and W. Baker, 1990: Global numerical weather prediction at the 
National Meteorological Center. Bull. Amer. Meteor. Soc., 71, 1410-1428.

Kaplan, L. D., 1959: Inference of atmospheric structure from remote radiation measurements. J. Opt. Soc. Am., 49, 1004-1007.

King, J. I. F., 1956: The radiative heat transfer of planet Earth. In "Scientific uses of Earth satellites", Univ. of Michigan Press. Ann Arbor, pp.133-136.

Kuo, Y.-H., E. G. Donall, and M. A. Shapiro, 1987: Feasibility of short-term numerical weather prediction using observations from a network of profilers. Mon. Wea. Rev., 115, 2402 2426.

Liou, K. N., 1980: An introduction to atmospheric radiation. Academic Press, New York, 392pp.

Lyne, W. H., R. Swinbank, and N. T. Birch, 1982: A data assimilation experiment and the global circulation during the FGGE special observing periods. Quart. J. Roy. Meteor. Soc., 108, 575-594.

Manabe, S., 1969: Climate and the ocean circulation: I. The atmospheric circulation and the hydrology of the earth's surface. Mon. Wea. Rev., 97, 739-774.

Menzel, W. P., and J. F. W. Purdom, 1994: Introducing GOES-I: The first of a new generation of geostationary operational environmental satellite. Bull. Amer. Meteor. Soc., 75, 757 781 .

Morel, P., 1981: An overview of meteorological data assimilation. Dynamic Meteorology: Data assimilation methods. In: L. Bengtsson, M. Ghil and E. Kallen (Eds.), SpringVerlag, 5-16.

$\emptyset$ kland, H., 1970: On the adjustment toward balance in primitive equation weather prediction models. Mon. Wea. Rev., 98, 271-279.

Pan, H.-L., 1990: A simple parameterization scheme of evpotranspiration over land for the NMC medium-range forecast model. Mon. Wea. Rev., 118, 2500-2512.

Pan, Z., E. Takle, M. Segal, and R. Turner, 1996: Influences of model parameterization schemes on the response of rainfall to soil moisture in the central United States. Mon. Wea. Rev., 124, 1786-1802.

Parrish, D. F., and J. C. Derber, 1992: The National Meterological Center's spectral statistical interpolation analysis system. Mon. Wea. Rev., 120, 1747-1766.

Roads, J. O., and T. N. Maisel, 1991: Evaluation of the National Meteorological Center's medium-range forecast model precipitation forecasts. Wea. Forecasting, 6, 123-132.

Rossby, C.-G., 1937: On the mutual adjustment of pressure and velocity distributions in certain simple current systems, 1. J. Mar. Res., 1, 15-28.

Rossby, C.-G., 1938: On the mutual adjustment of pressure and velocity distributions in certain simple current systems, 2. J. Mar. Res., 2, 239-263.

Schoenstadt, A. L., 1977: The effect of spatial discretization on the steady state and ransient behavior of a dispersive wave equation. J. Comput. Phys., 21, 166-177.

Segal, M., R. W. Arritt, C, Clark, R. Rabin, and J. M. Brown, 1995: Scaling evaluation of the effect of surface characteristics on potential for deep convection over uniform terrain. Mon. Wea. Rev., 123, 383-400.

Smith, W. L., 1970: Iterative solution of the radiative transfer equation for temperature and absorbing gas profiles of an atmosphere. Appl. Opt., 9, 1993-1999. 
Smith, W. L., 1983: The retrieval of atmospheric profiles from VAS geostationary radiance observations. J. Atmos. Sci., 40, 2025-2035.

Stauffer, D. R., and N. L. Seaman, 1990: Use of four-dimensional data assimilation in a limited-area mososcale model. Part I: Experiments with synoptic-scale data. Mon. Wea. Rev., 118, 1250-1277.

Stauffer, D. R., and N. L. Seaman, 1991: Use of four-dimensional data assimilation in a limited-area mesoscale model. Part II: Effects of data assimilation within the planetary boundary layer. Mon. Wea. Rev., 119, 734-753.

Stokes, G. M., and S. E. Schwartz, 1994: The atmospheric radiation measurement (ARM) program: Programmatic background and design of the cloud and radiation test bed. Bull. Amer. Meteor. Soc., 75, 1201-1221.

Thompson, O. E., 1992: Regularizing the satellite temperature-retrieval problem through sigular-value decomposition of the radiative transfer physics. Mon. Wea. Rev., 120, 2314-2328.

\section{APPENDIX}

A brief outline of the mathematical formulation of Gal-Chen's FDDA algorithm

The FDDA technique proposed by Gal-Chen (1983) seeks to improve a model's performance via the improvement of initial condition by making good use of remotely sensed data from satellites. The concept of Gal-Chen's FDDA technique is that:

(1) the model's predicted temperature $\left(\mathrm{T}^{\mathrm{p}}\right)$ and the adjusted temperature $\left(\mathrm{T}^{\mathrm{a}}\right)$ are as close as possible to each other during the data assimilation period;

(2) the adjusted temperature match the observations by the GOES sounders at the same time.

The GOES continuously operating sounder can be approximated by a set of linear equations such as,

$$
\sum_{\mathrm{n}} \mathrm{w}_{\mathrm{v}}^{\mathrm{n}} \mathrm{T}_{\mathrm{n}}=\mathrm{I}_{\mathrm{v}}, \mathrm{v}=1,2, \ldots, \mathrm{M}
$$

where

$T_{n}$ is the temperature at a particular vertical level $n, n=1,2, . ., N_{z}, N_{z}$ the number of total vertical levels;

$\mathrm{v}$ is an index for some specific constraint; or equivalently, a particular band of frequencies; $M$ is the total number of constraints, or equivalently, the number of infrared channels (e.g., $M=18$ for the sounders deployed on GOES-8 and GOES-9);

$I_{v}$ is a given number of the observed radiances;

$\mathrm{W}_{\mathrm{v}}^{\mathrm{n}}$ are the weights for a particular frequency, which can be obtained $a$ priori.

When one divides the model's vertical domain into two mutually exclusive thickness layers, layer 1 and layer 2, (e.g., ground surface-500 mb and 500-50 mb as shown in Fig. 2.1) then $I_{v}$ is the layer-mean temperature of either layer 1 or layer 2 . The weights $\left(w_{v}^{n}\right)$ of temperature $T_{n}$ will be zero if the vertical $n^{\text {th }}$ level of the model does not belong to that layer. Any 
vertical level of the model can only be either in layer 1 or layer 2 .

Mathematically speaking, to achieve the concept of (1) and (2) as stated above, one needs to minimize the following variational problem:

$$
\sum_{n}\left(T_{n}^{a}-T_{n}^{\rho}\right)^{2}=\min (\text { imum }),
$$

subject to the constraints set by satellite measurements:

$$
\sum_{n} w_{v}^{n} T_{n}=I_{v} \text {. }
$$

(A2) and (A3) can be solved by the Lagrangian multiplier method, i.e.,

$$
\sum_{\mathrm{n}}\left(\mathrm{T}_{\mathrm{n}}^{\mathrm{a}}-\mathrm{T}_{\mathrm{n}}^{\mathrm{p}}\right)^{2}+\sum_{\mathrm{n}} \sum_{\mathrm{v}} \lambda^{\mathrm{v}} \mathrm{w}_{\mathrm{v}}^{\mathrm{n}} \mathrm{T}_{\mathrm{n}}^{\mathrm{a}}=\mathrm{F},
$$

in which $T_{n}^{a}$ (the adjusted temperature) is unknown.

Minimization of $F$ requires that $\frac{\partial F}{\partial T_{n}^{a}}=0=0$.

$$
\begin{aligned}
& \Rightarrow \sum_{n}\left[2\left(T_{n}^{a}-T_{n}^{p}\right)+\sum_{v} \lambda^{v} w_{v}^{n}\right]=0 . \\
& \Rightarrow 2\left(T_{n}^{a}-T_{n}^{p}\right)+\sum_{v} \lambda^{v} w_{v}^{n}=0,
\end{aligned}
$$

and subject to the constraints provided by satellite measurements:

$$
\sum_{n} w_{v}{ }_{v}^{n} T_{n}^{a}=I_{v}^{a},
$$

with $I_{v}^{a}$ being the observed radiance.

The variational problem is to solve for the Lagrangian multiplier $\lambda$ and to get $T_{n}^{2}$ based on the knowledge of $T_{n}^{p}, \lambda$ and $w_{v}^{n}$ within each model thickness layer. To simplify the problem, one can assume that (i) the layers of the model's atmosphere are mutually exclusive, e.g., the top and bottom half layers of the model's atmosphere are independent to each other; (ii) the weights $\left(w_{v}^{n}\right)$ in a specific layer are equal to each other, i.e., if there are $k$ model levels in layer one then $w_{v}^{\mathrm{n}}$ is $1 / \mathrm{k}$, accordingly. Assuming there is only one band of frequency of satellite measurement in this layer, (A6) can be rewritten as:

$$
\begin{array}{r}
2\left(T_{n}^{a}-T_{n}^{p}\right)+\lambda w_{v}^{n}=0, \\
\text { or } \quad 2\left(T_{n}^{a}-T_{n}^{p}\right)+\lambda \frac{1}{k}=0,
\end{array}
$$

and the constraint (A7) becomes:

$$
\frac{1}{\mathrm{k}} \sum_{\mathrm{n}} \mathrm{T}_{\mathrm{n}}^{\mathrm{a}}=\mathrm{I}_{\mathrm{v}}^{\mathrm{a}}=\text { mean temperature (or radiance) detected by satellite for thickness }
$$

layer 1 (or layer 2, etc.) . 
Multiplying (A9) by $1 / \mathrm{k}$ and summing over all $\mathrm{n}$ levels in layer 1 :

$$
\sum_{\mathrm{n}} \frac{1}{\mathrm{k}}\left[2\left(\mathrm{~T}_{\mathrm{n}}^{\mathrm{a}}-\mathrm{T}_{\mathrm{n}}^{\mathrm{p}}\right)+\lambda \frac{1}{\mathrm{k}}\right]=0
$$

Denoting $\mathrm{I}_{\mathrm{v}}^{\mathrm{a}}$ by $\left\langle\mathrm{T}^{\mathrm{s}}\right\rangle_{\mathrm{v}}$, and similarly, $\left\langle\mathrm{T}^{\mathrm{p}}\right\rangle_{\mathrm{v}}=\frac{1}{\mathrm{k}} \sum_{\mathrm{n}} \mathrm{T}_{\mathrm{n}}^{\mathrm{\rho}}$, (A10) becomes

$$
2\left[\left\langle\mathrm{~T}^{\mathrm{s}}\right\rangle_{\mathrm{v}}-\left\langle\mathrm{T}^{\mathrm{p}}\right\rangle_{\mathrm{v}}\right]+\mathrm{n} \lambda \frac{1}{\mathrm{k}^{2}}=0
$$

By assumption (ii), if there are $n$ levels in layer 1 and each level has equal weight, then $n=k$ and (A11) will become,

$$
-\frac{\lambda}{\mathrm{k}}=2\left[\left\langle\mathrm{~T}^{\mathrm{s}}\right\rangle_{\mathrm{v}}-\left\langle\mathrm{T}^{\mathrm{p}}\right\rangle_{\mathrm{v}}\right]
$$

By (A9) one gets,

$$
-\frac{\lambda}{\mathrm{k}}=2\left[\left\langle\mathrm{~T}^{\mathrm{s}}\right\rangle_{\mathrm{v}}-\left\langle\mathrm{T}^{\mathrm{p}}\right\rangle_{\mathrm{v}}\right]=2\left(\mathrm{~T}_{\mathrm{n}}^{\mathrm{a}}-\mathrm{T}_{\mathrm{n}}^{\mathrm{p}}\right)
$$

or, the adjusted temperature can be expressed as:

$$
\mathrm{T}_{\mathrm{n}}^{\mathrm{a}}=\mathrm{T}_{\mathrm{n}}^{\mathrm{p}}-\left\langle\mathrm{T}^{\mathrm{p}}\right\rangle_{\mathrm{v}}+\left\langle\mathrm{T}^{\mathrm{s}}\right\rangle_{\mathrm{v}},
$$

for layer 1 . Similarly arguments hold for layer 2 , layer3, etc.

To fulfill the concepts (1) and (2), therefore, one simply needs to replace the model's mean layer temperature with that retrieved from satellite measurements.

On the other hand, one notices that the use of the adjusted temperature $\left(T_{n}^{a}\right)$ will makes the corresponding geopotential height $\left(Z_{n}^{f}\right)$ no longer compatible with the momentum equations of the model. That is, the goepotential fields computed from $T_{n}^{a}$ are not in balance with the original equations of motion of the model. Therefore, there is a need to seek a geopotential $Z^{a}$ which is a mixture of the model's original geopotential heights $Z^{p}$ and the geopotential heights $\left(Z^{f}\right)$ calculated based on the adjusted temperature $\left(T^{a}\right)$ through hydrostatic approximation $\frac{\partial Z^{f}}{\partial \ln p}=-R T^{a}$. The final adjusted geopotential height $Z^{a}$ will (a) satisfy the momentum equations at least in a least square sense, and (b) be as close as possible to $Z^{\mathrm{f}}$ which contains the information from satellite measurements. The model's predicted geopotential $Z^{p}$ satisfy the following equations:

$$
\frac{\partial Z^{p}}{\partial x}=F ; \frac{\partial Z^{p}}{\partial y}=G
$$

where $\mathrm{F}$ and $\mathrm{G}$ are terms corresponding to the dynamics in momentum equations. Assuming $\ln \mathrm{p}$ is the vertical coordinate the final adjusted geopotential height $\left(\mathrm{Z}^{\mathrm{a}}\right)$ should then be the solution of the following variational problem: 


$$
\begin{aligned}
& \int_{\text {volumn }} \alpha\left\{\left[\frac{\partial Z^{\mathrm{a}}}{\partial \mathrm{x}}-\frac{\partial \mathrm{Z}^{\mathrm{f}}}{\partial \mathrm{x}}\right]^{2}+\left[\frac{\partial \mathrm{Z}^{\mathrm{a}}}{\partial \mathrm{y}}-\frac{\partial \mathrm{Z}^{\mathrm{f}}}{\partial \mathrm{y}}\right]^{2}\right\}+\beta\left\{\left[\frac{\partial \mathrm{Z}^{\mathrm{a}}}{\partial \mathrm{x}}-\frac{\partial \mathrm{Z}^{\mathrm{p}}}{\partial \mathrm{x}}\right]^{2}+\left[\frac{\partial \mathrm{Z}^{\mathrm{a}}}{\partial \mathrm{y}}-\frac{\partial \mathrm{Z}^{\mathrm{p}}}{\partial \mathrm{y}}\right]^{2}\right\} \\
&+\gamma\left[\frac{\partial \mathrm{Z}^{\mathrm{a}}}{\partial \ln \mathrm{p}}-\frac{\partial \mathrm{Z}^{\mathrm{f}}}{\partial \ln \mathrm{p}}\right]^{2} \mathrm{dxdydln} \mathrm{p}=\text { minimum }
\end{aligned}
$$

where $\alpha, \beta$, and $\gamma$ are empirical weights.

Applying the first variation on (A16) to get,

$$
\begin{gathered}
\int_{\text {volume }}\left[2 \alpha\left(\frac{\partial Z^{\mathrm{a}}}{\partial \mathrm{x}}-\frac{\partial \mathrm{Z}^{\mathrm{f}}}{\partial \mathrm{x}}\right) \frac{\partial \delta Z^{\mathrm{a}}}{\partial \mathrm{x}}+2 \alpha\left(\frac{\partial \mathrm{Z}^{\mathrm{a}}}{\partial \mathrm{y}}-\frac{\partial \mathrm{Z}^{\mathrm{f}}}{\partial \mathrm{y}}\right) \frac{\partial \delta \mathrm{Z}^{\mathrm{a}}}{\partial \mathrm{y}}+2 \beta\left(\frac{\partial \mathrm{Z}^{\mathrm{a}}}{\partial \mathrm{x}}-\frac{\partial \mathrm{Z}^{\mathrm{p}}}{\partial \mathrm{x}}\right) \frac{\partial \delta \mathrm{Z}^{\mathrm{a}}}{\partial \mathrm{x}}\right. \\
+2 \beta\left(\frac{\partial \mathrm{Z}^{\mathrm{a}}}{\partial \mathrm{y}}-\frac{\partial \mathrm{Z}^{\mathrm{p}}}{\partial \mathrm{y}}\right) \frac{\partial \delta \mathrm{Z}^{\mathrm{a}}}{\partial \mathrm{y}}+2 \gamma\left(\frac{\partial \mathrm{Z}^{\mathrm{a}}}{\partial \ln \mathrm{p}}-\frac{\partial \mathrm{Z}^{\mathrm{f}}}{\partial \ln \mathrm{p}}\right) \frac{\partial \delta Z^{\mathrm{a}}}{\partial \ln \mathrm{p}} \mathrm{dV}=0 .
\end{gathered}
$$

After some rearrangement of the terms in (A17) and with the arbitrariness of the volume integration (see Chen 1996 for details), one gets:

$$
(\alpha+\beta) \nabla_{\mathrm{H}}^{2} Z^{\mathrm{a}}+\gamma \frac{\partial^{2} Z^{\mathrm{a}}}{\partial^{2} \ln \mathrm{p}}=\alpha \nabla_{\mathrm{H}}^{2} Z^{\mathrm{f}}+\beta \nabla_{\mathrm{H}}^{2} Z^{\mathrm{p}}+\gamma \frac{\partial^{2} Z^{\mathrm{f}}}{\partial^{2} \ln \mathrm{p}},
$$

with $\nabla_{\mathrm{H}}^{2}=\frac{\partial^{2}}{\partial \mathrm{x}^{2}}+\frac{\partial^{2}}{\partial \mathrm{y}^{2}}$.

The associated boundary conditions in $\mathrm{x}, \mathrm{y}$, and $\mathrm{z}$ directions are (A19), (A20), and (A21), respectively:

$$
\begin{aligned}
\frac{\partial Z^{\mathrm{a}}}{\partial \mathrm{x}} & =\frac{\alpha}{\alpha+\beta} \frac{\partial Z^{\mathrm{f}}}{\partial \mathrm{x}}+\frac{\beta}{\alpha+\beta} \frac{\partial \mathrm{Z}^{\mathrm{p}}}{\partial \mathrm{x}}, \\
\frac{\partial Z^{\mathrm{a}}}{\partial \mathrm{y}} & =\frac{\alpha}{\alpha+\beta} \frac{\partial \mathrm{Z}^{\mathrm{f}}}{\partial \mathrm{y}}+\frac{\beta}{\alpha+\beta} \frac{\partial Z^{\mathrm{p}}}{\partial \mathrm{y}}, \\
Z^{\mathrm{a}} & =Z^{\mathrm{p}} .
\end{aligned}
$$

That is, in order to have the geopotential fields still satisfy the momentum equations after the adjustment of the model's temperature, one needs to solve the Poisson equation of (A18) with the necessary boundary conditions of (A19), (A20), and (A21). In this approach the empirical weights; $\alpha, \beta$, and $\gamma$ in (A18) are assigned to be $0.6,0.1$, and 0.3 , respectively (GalChen et al. 1987). 